UNITED STATES DEPARTMENT OF THE INTERIOR

GEOLOGICAL SURVEY

\title{
GEOPHYSICAL LOGS OF 20 HOLES DRILLED IN 1977 IN THE YAMPA COAL FIELD, HAMILTON, HORSE GULCH, AND PAGODA QUADRANGLES, MOFFAT COUNTY, COLORADO
}

\section{By}

Richard F. Meyer

Open-File Report 78-366

1978

This report has not been edited for conformity with Geological Survey editorial standards or stratigraphic nomenclature. 
Introduction--_--_-_-_-

Geophysical logs--_- 9

\section{ILLUSTRATIONS}

Figure 1. Index map of figures 2 through 6, Moffat County, Colorado--

2-6. Location maps of drill holes, Moffat County, Colorado:

2. Central part of Horse Gulch quadrangle--------- 4

3. East-central part of Horse Gulch quadrangle----- 5

4. Central part of Hamilton quadrangle--- 6

5. Southeastern part of Hamilton quadrangle------ 7

6. Pagoda quadrangle-- 8 
GEOPHYSICAL LOGS OF 20 HOLES DRILLED IN 1977 IN THE YAMPA COAL FIELD, HAMILTON, HORSE GULCH, AND PAGODA QUADRANGLES, MOFFAT COUNTY, COLORADO

By Richard F. Meyer

\section{INTRODUCTION}

Under contract no. 14-08-0001-15788, awarded by the U.S. Geological Survey, McCabe Brothers Drilling, Inc. and Hugh Harris Drilling Co., Inc. drilled 20 holes in the Yampa coal field, Moffat County, Colorado (figs. 1-6). A11 of the holes had diameters of between 5 and 5-1/4 inches and were drilled with truck-mounted rotary dril1 rigs between July 27 and October 13, 1977.

The purpose of this project was to obtain information about the thickness, quality, depth, and continuity of coal beds in. the Upper Cretaceous Williams Fork Formation in the Yampa coal field. Many of the holes reached the Trout Creek Sandstone Member of the Upper Cretaceous Iles Formation, and a few holes were drilled through the Trout Creek Sandstone and intersected some of the coals in the upper part of the Iles Formation. All of the holes were located within tracts of interest to industry for future coal leasing.

U.S. Geological Survey personnel selected the drill-hole locations, obtained permission for access, supervised the drilling and geophysical logging, took part in the pre-drilling site inspections by the Bureau of Land Management, and supervised and assisted in the post-drilling reclamation. Post-drilling reclamation met the Bureau of Land Management's specifications.

Under contract to McCabe and Harris, a total of 21,063 feet of hole were geophysically logged by the following companies: (1) Rocky Mountain Logging Service, 15 holes for a total of 15,556 feet; (2) Savage Scientific, Inc., 3 holes for a total of 3,151 feet; and (3) Digilog, Inc., 2 holes for a total of 2,356 feet. 
Some holes, drilled with foam, had to be filled with light mud to obtain resistance and spontaneous potential logs. This was accomplished by first logging the holes to the surface, including the dry upper parts where only the natura1-gamma and density (gamma-gamma) logs could be obtained. Then, with the probe out of the hole, an attempt was made to fill the hole with liquid. Finally, the upper part of the hole was logged again. This procedure was often repeated several times, resulting in several logs for the top part of each hole. Sometimes these multiple runs were recorded on the same chart paper and sometimes on a separate chart paper. In this report, when several chart papers were used, the entire first run is shown first and the following runs are shown in the order in which they were made.

The geophysical logs were originally run at a vertical scale of 1 inch to 10 feet, but to facilitate reproduction of this report, they were reduced to 1 inch to 50 feet. A11 measurements are in feet; to convert to meters, multiply by 0.3048 . 
R. $93 \mathrm{~W}$.

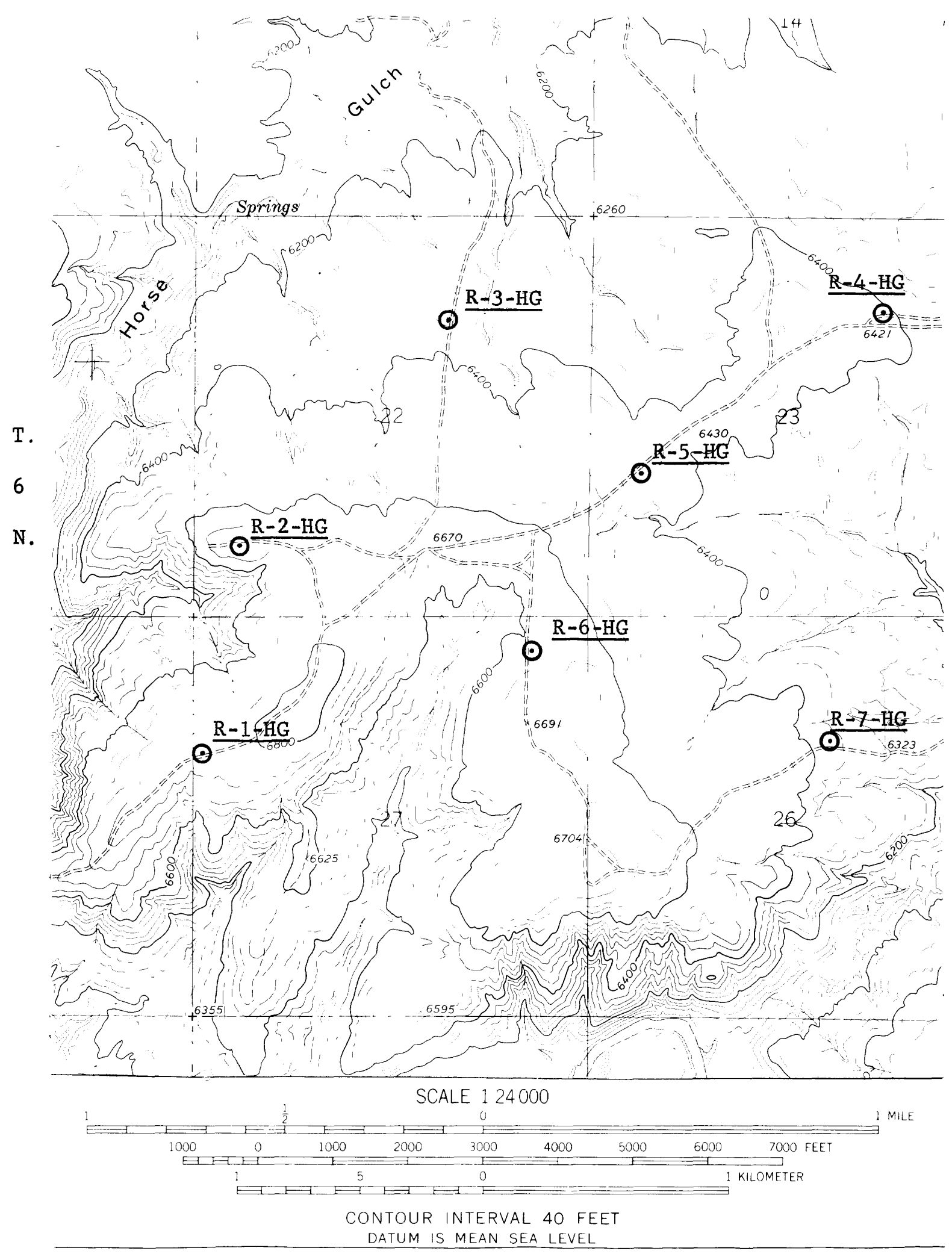

Figure 2.--Location of drill holes in the central part of the Horse Gulch quadrangle, Moffat County, Colorado. 


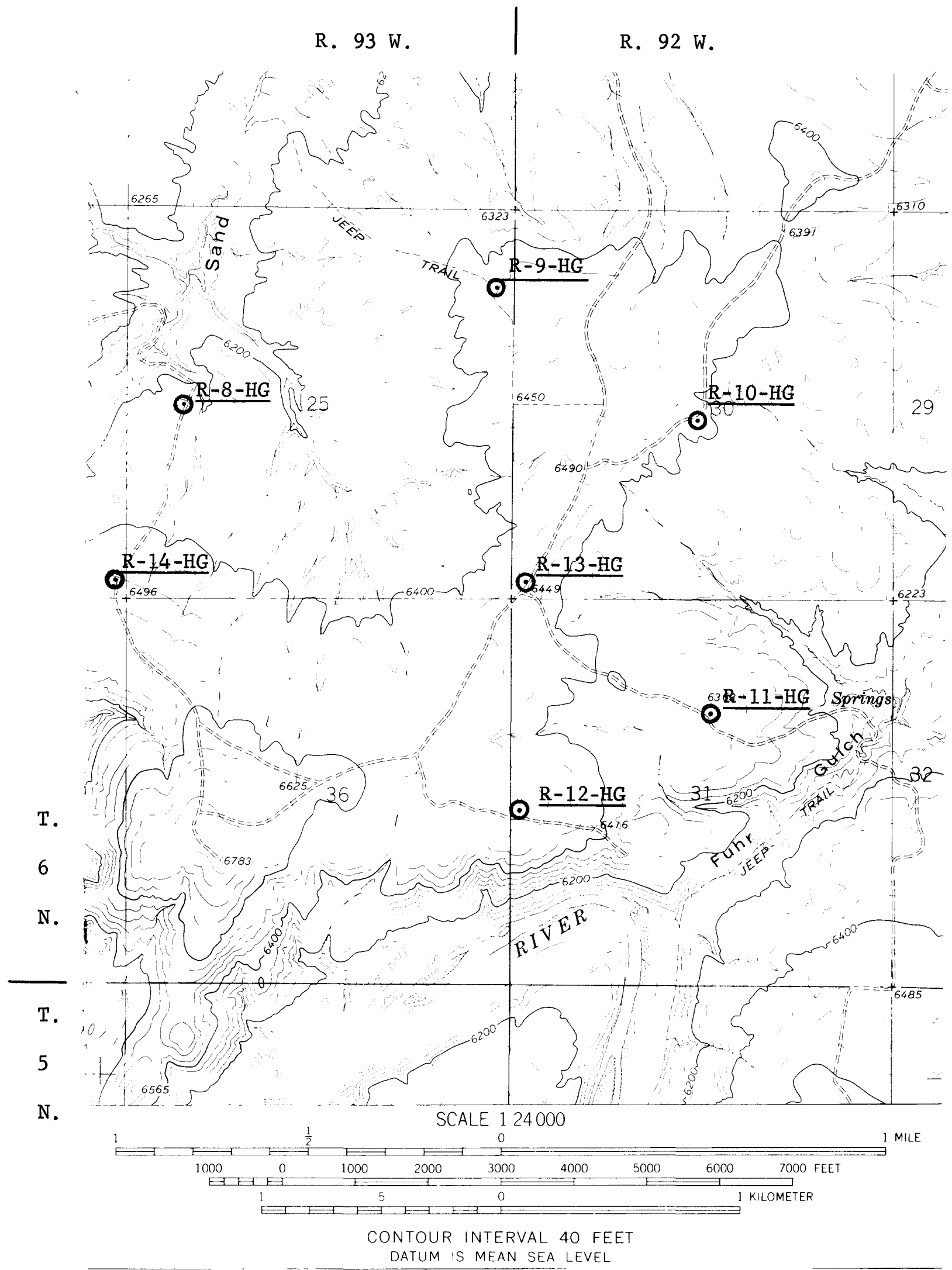

Figure 3.--Location of drill holes in the east-central Horse Gulch quadrangle, Moffat County, Colorado. 


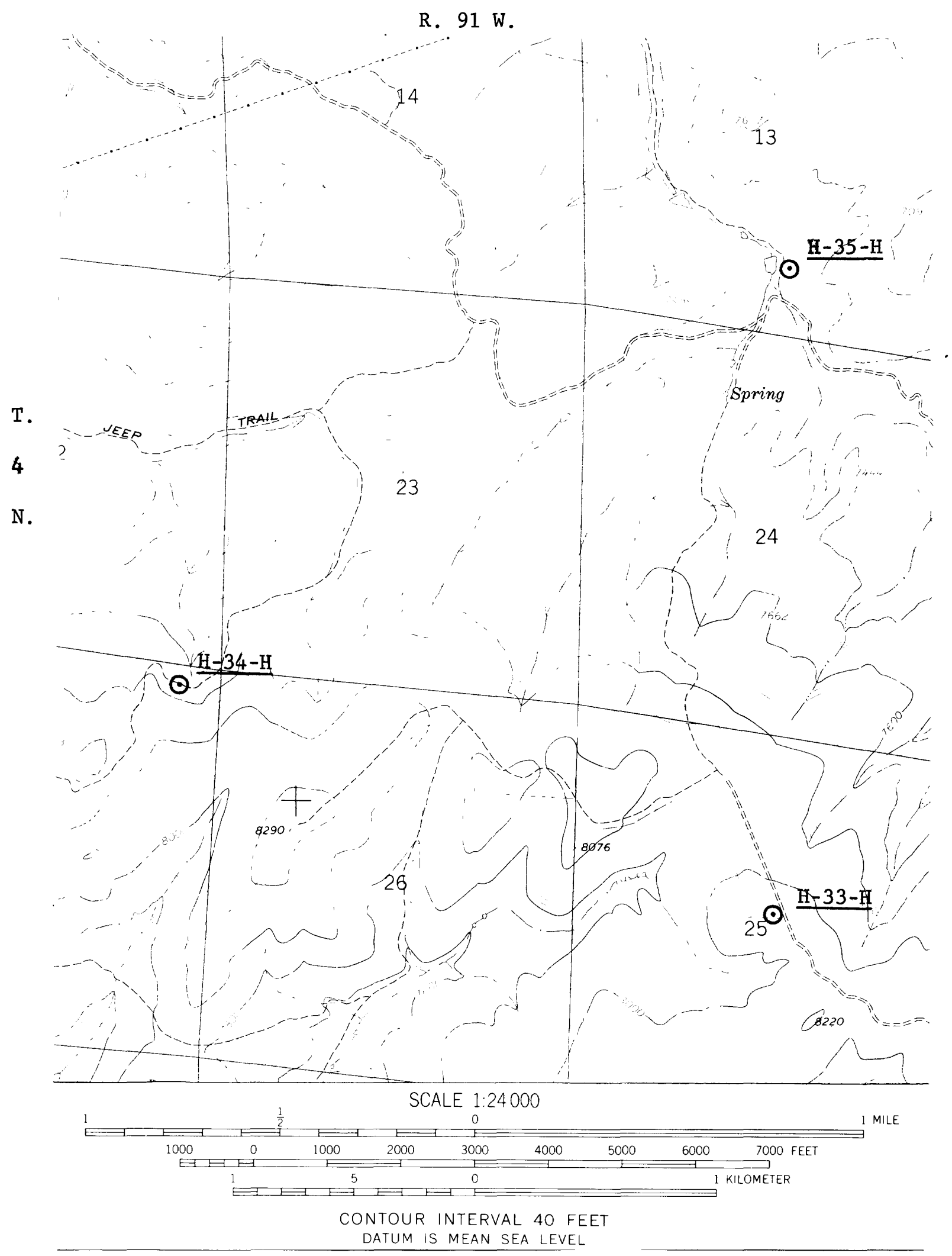

Figure 4.--Location of drill holes in the central part of the Hamilton quadrangle, Moffat County, Colorado. 


\section{R. $90 \mathrm{~W}$.}

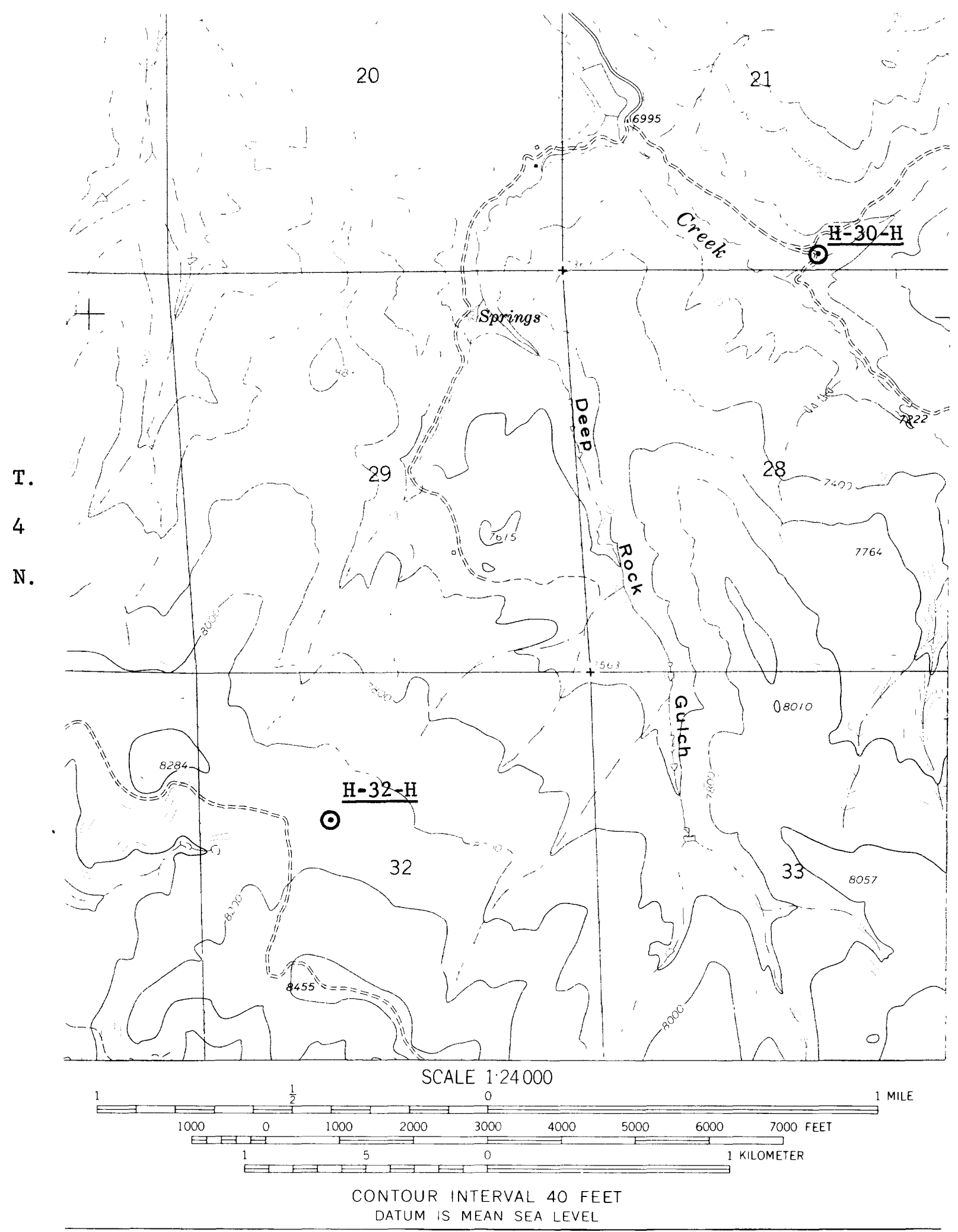

Figure 5.--Location of drill holes in the southeastern part of the Hamilton quadrangle, Moffat County, Colorado. 
U. S. GEOLOGICAL SURVEY

GEOPHYSICAL LOG, MOFFAT COUNTY, COLORADO

HORSE GULCH QUADRANGLE

Hole no. $\mathrm{R}-1-\mathrm{HG}$

Date logged $8 / 20 / 77$

Ground elevation $6,775^{\prime}$

T. 6 N., R. 93 W., Sec. $27: 100^{\prime}$ f $\mathrm{w} 1,3,500^{\prime} \mathrm{f} \quad 1$

Drilling medium foam Drilled depth 1,105' Fluid level 748'

Logging company_Rocky Mtn. Logging speed_20'/min. Logged depth 1,089'

$\begin{array}{lll}\text { Natural gamma (G) } & \text { Scale } 25 \mathrm{cps} / \mathrm{in} & \text { T.C. } 1 \\ \text { Spontaneous potential (SP) } & \text { Scale } 100 \mathrm{mv} / \mathrm{in} \\ \text { Single point resistance (R) Scale } 2 \mathrm{ohms} / \mathrm{in} ; 5 \mathrm{ohms} / \mathrm{in} \\ \text { Density (gamma-gamma) (D) } & \text { Scale } 5 \mathrm{~K} \mathrm{cps} / \mathrm{in} & \text { T.C. } 1\end{array}$

Remarks: Hole drilled "blind" (i.e. no return of cuttings) from 25' to 1,105'.

Resistance scale changed at $765^{\prime}$ to 5 ohms/in.

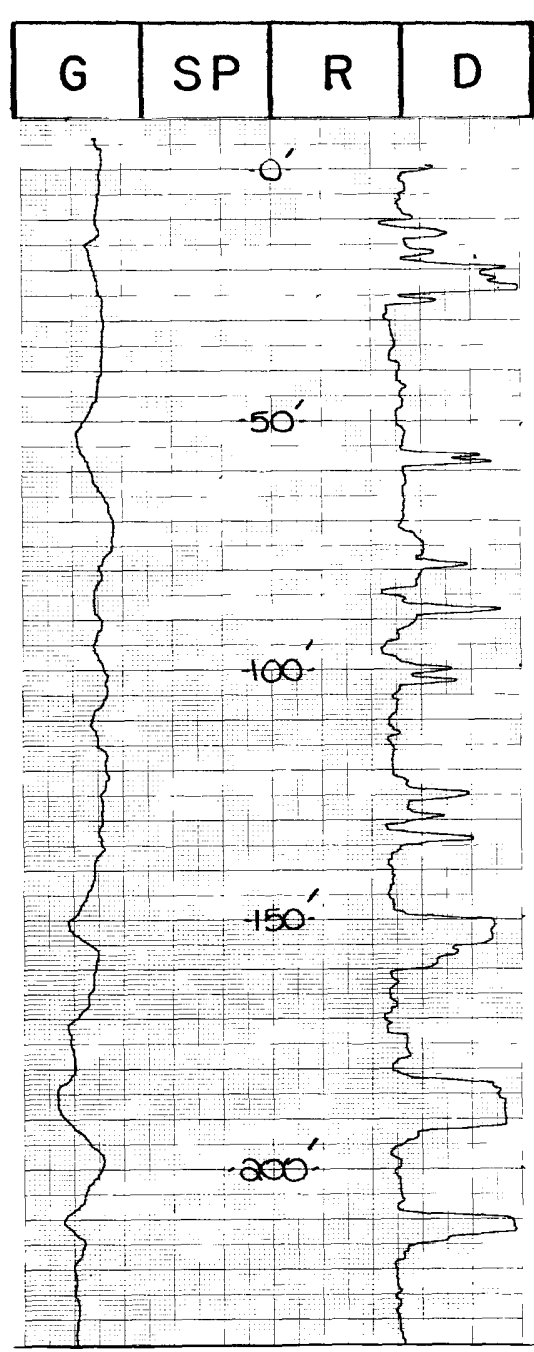

$10^{\prime} \prod^{\prime \prime}$

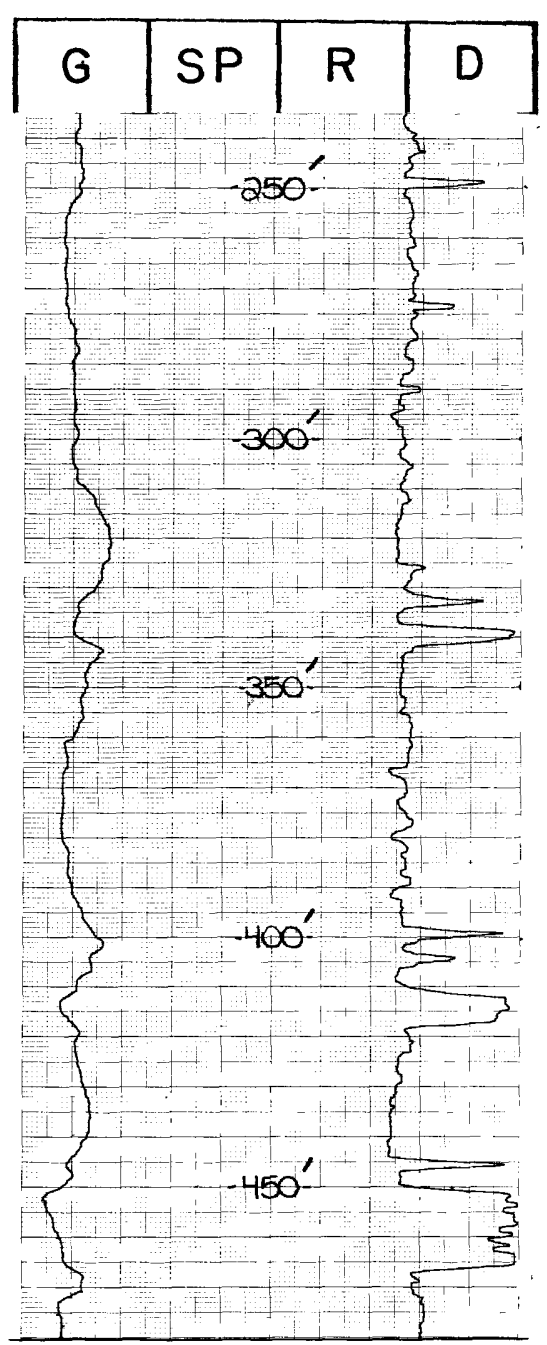


R. $90 \mathrm{~W}$.

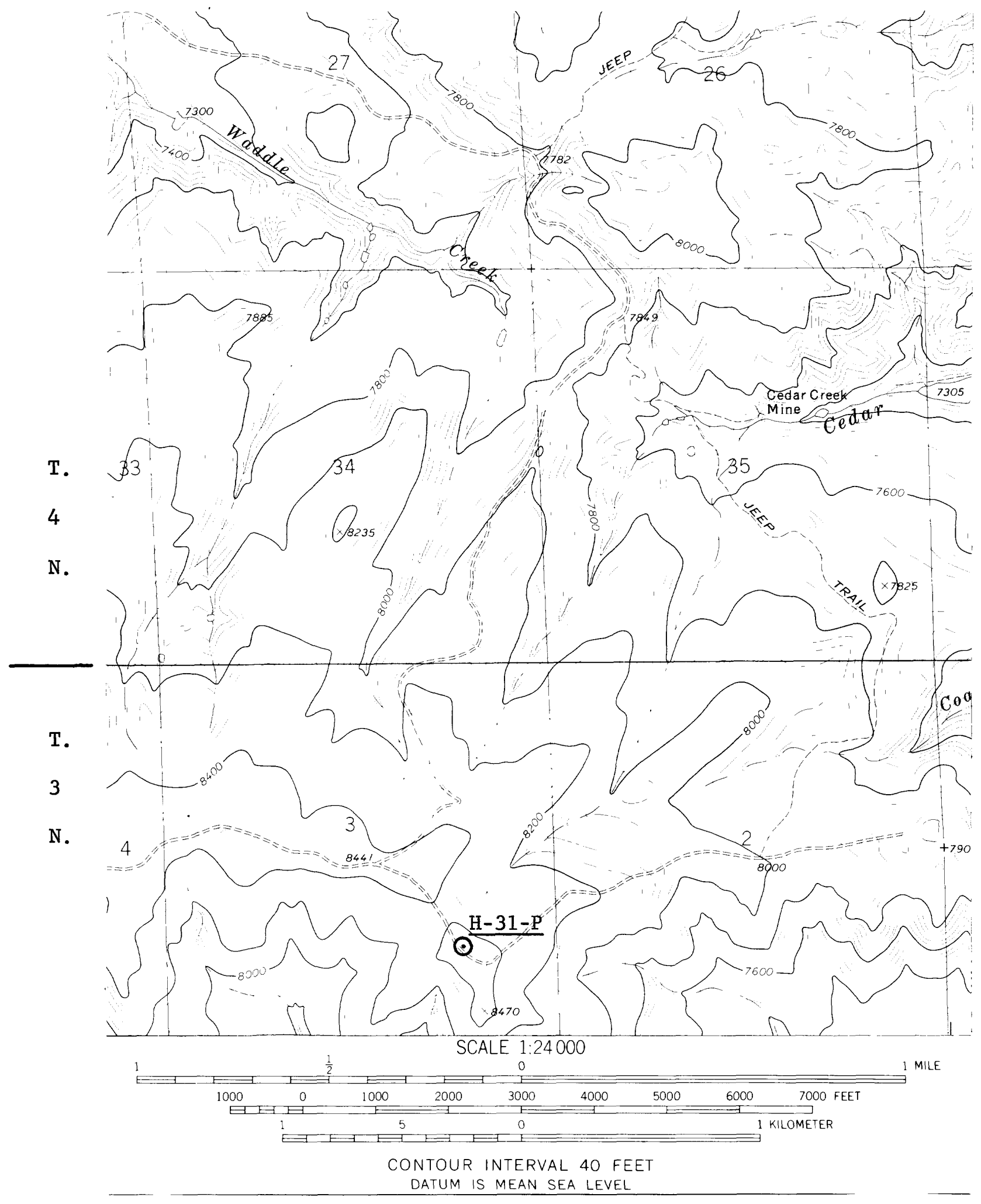

Figure 6.--Location of drill holes in the Pagoda quadrangle, Moffat County, Colorado. 
Hole no. R-1-HG (continued)
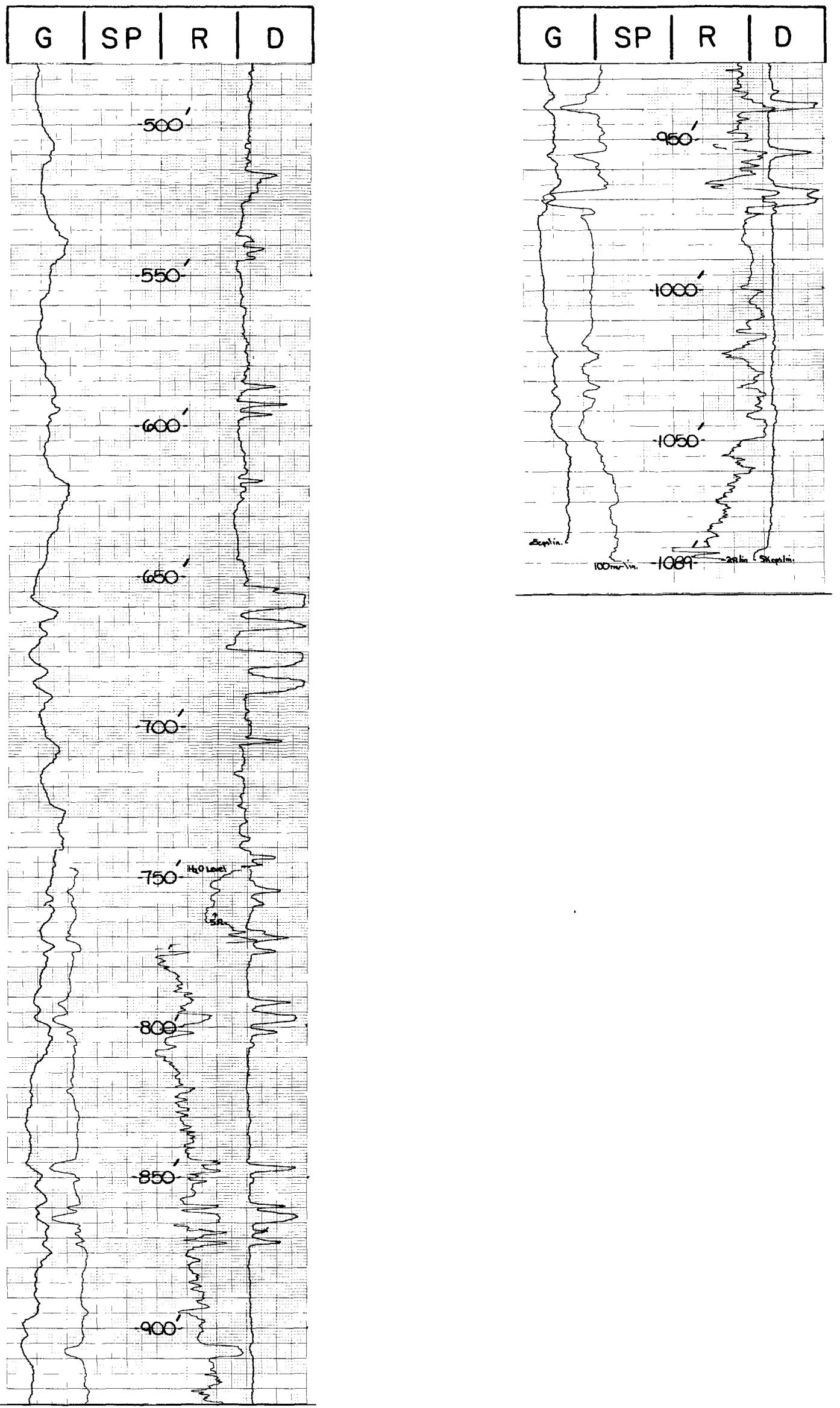
U. S. GEOLOGICAL SURVEY

GEOPHYSICAL LOG, MOFFAT COUNTY, COLORADO

HORSE GULCH QUADRANGLE

Hole no. R-2-HG Date logged 8/24/77_Ground elevation 6,650'

T. 6 N., R. 93 W., Sec. $22: \quad 600^{\prime}$ f w $1,940^{\prime}$ f $\mathrm{s} 1$

Drilling medium foam Drilled depth 1,265' Fluid level_ 595'

Logging company_ Digilog_Logging speed 20'/min. Logged depth 1,254'

Natural gamma (G)

Scale $10 \mathrm{cps} /$ in

T.C. 2

Spontaneous potential (SP) Scale $30 \mathrm{mv} / \mathrm{in}$

Single point resistance (R) Scale $30 \mathrm{ohms} /$ in

Density (gamma-gamma) (D) Scale $50 \mathrm{cps} /$ in T.C. 1

Remarks: None

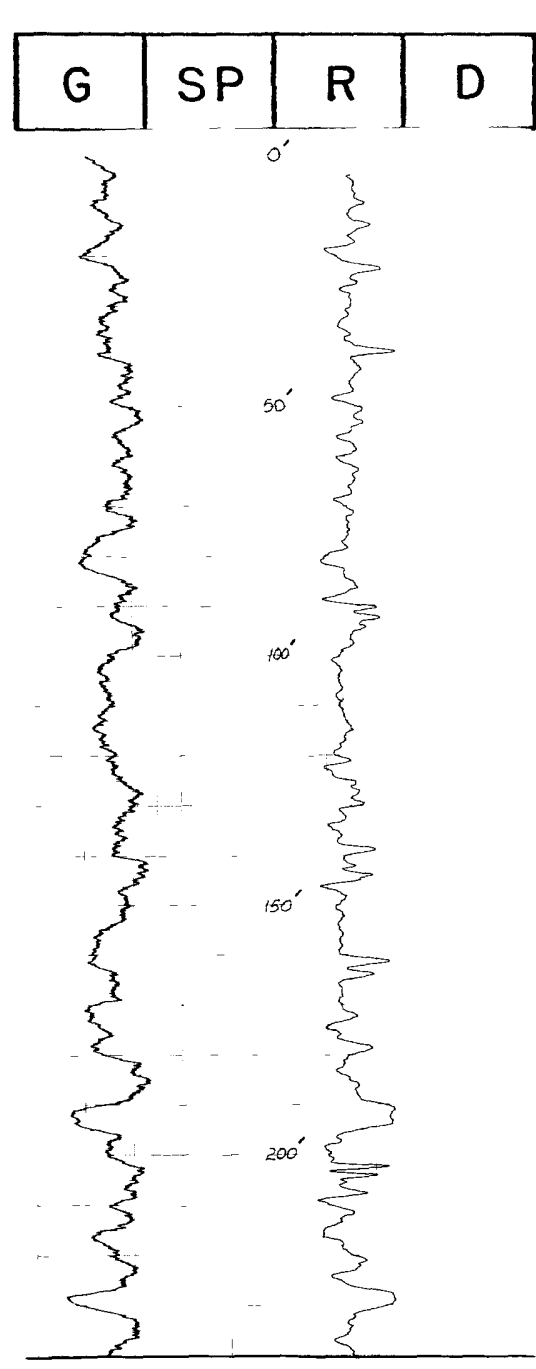

$10^{\prime} \Gamma^{\prime \prime}$

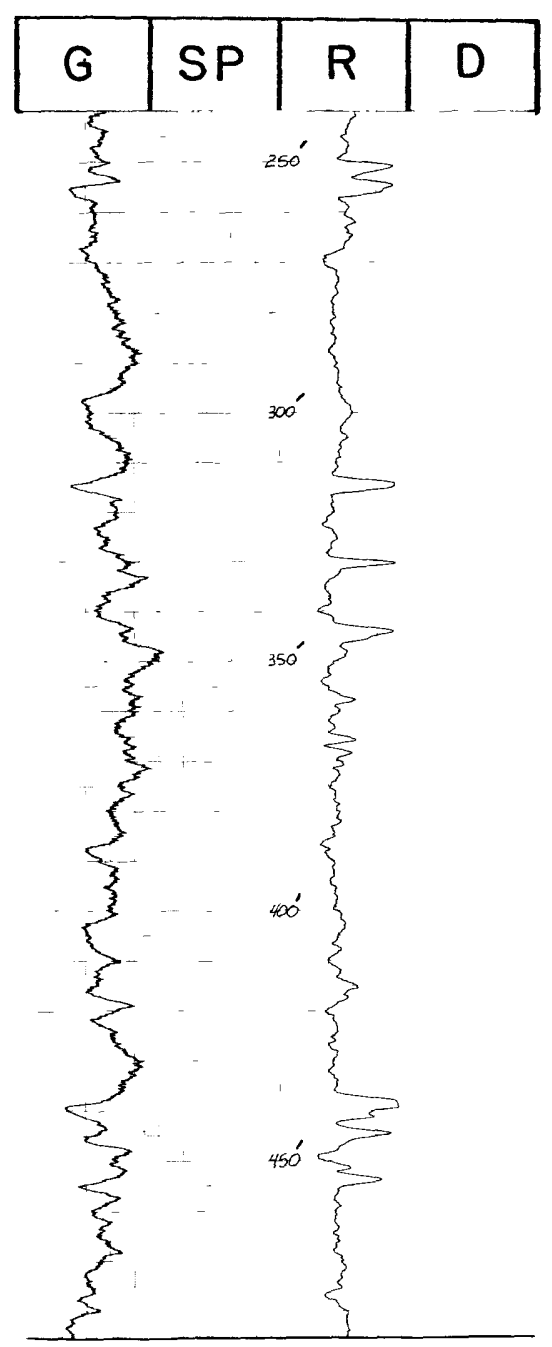




\section{U.S. GEOLOGICAL SURVEY \\ GEOPHYSICAL LOG, MOFFAT COUNTY, COLORADO HORSE GULCH QUADRANGLE}

Hole no. R-3-HG Date logged 9/1/77_Ground elevation 6,350'

T. 6 N., R. 93 W., Sec.22 : 3,350' f w 1, 3,910'f s 1

Drilling medium mud Drilled depth 967' Fluid level 68' (first run)

Logging company Savage_Logging speed 20'/min. Logged depth 967'

$\begin{array}{lll}\text { Natural gamma (G) } & \text { Scale } \frac{5 \mathrm{cps} / \mathrm{in}}{100 \mathrm{cps} / \mathrm{in}} \\ \text { Density (gamma-gamma) } & \text { (D) } & \text { Scale } \frac{2}{10} \\ \text { Spontaneous potential (SP) } & \text { Scale } 50 \mathrm{mv} / \mathrm{in} ; 100 \mathrm{mv} / \mathrm{in} \\ \text { Single point resistance (R) } & \text { Scale } 50 \mathrm{ohms} / \mathrm{in} ; 100 \mathrm{ohms} / \mathrm{in}\end{array}$

Remarks: Fluid level at $67^{\prime}$ on first run. The hole was then filled with mud and

rerun from 115'. Spontaneous potential changed to $100 \mathrm{mv} /$ in at 48'. Resistance changed to $100 \mathrm{ohms} /$ in at $115^{\prime}$ for rerun.
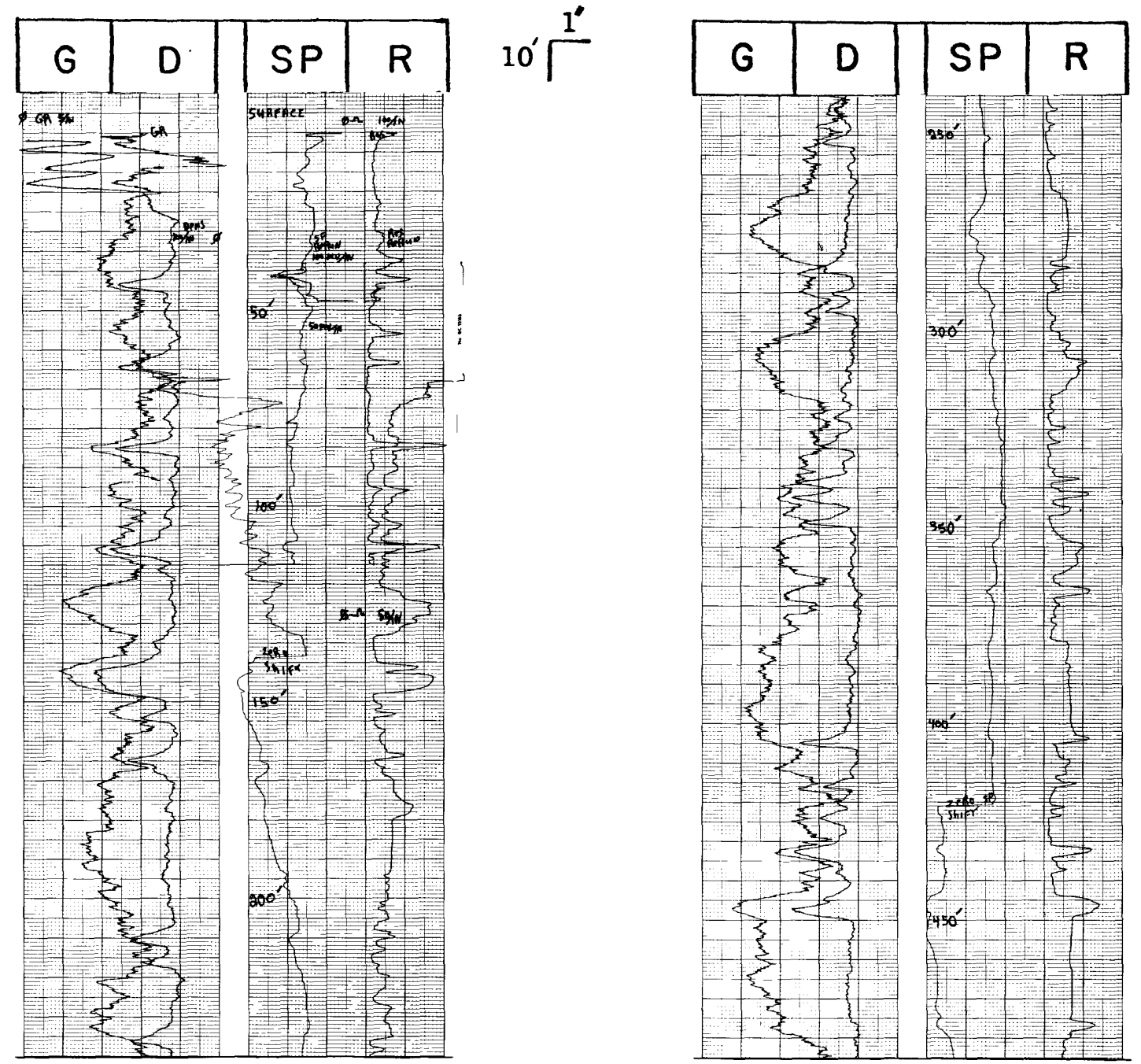
Hole no. R-2-HG

(continued)
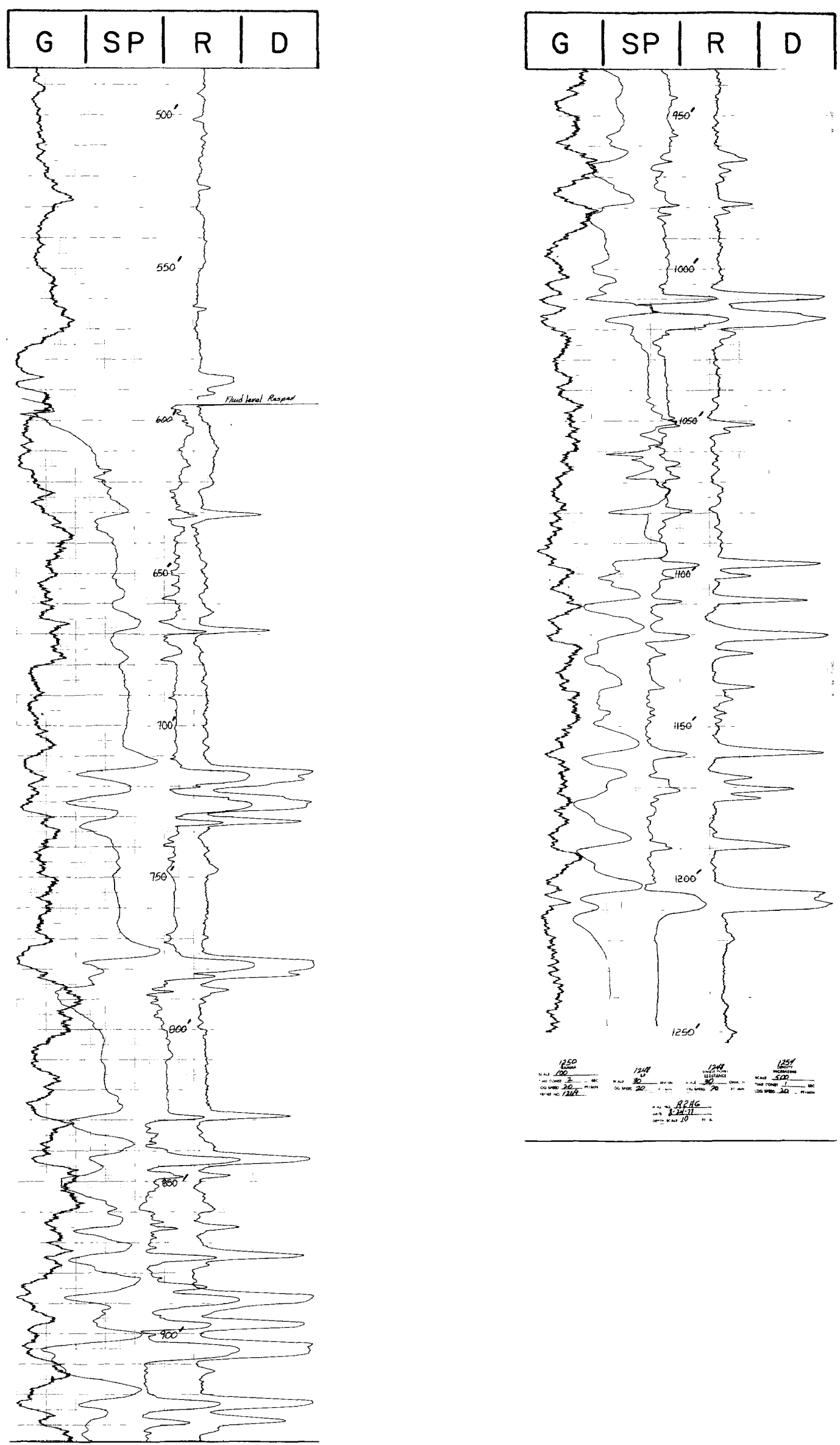
Hole no. R-3-HG

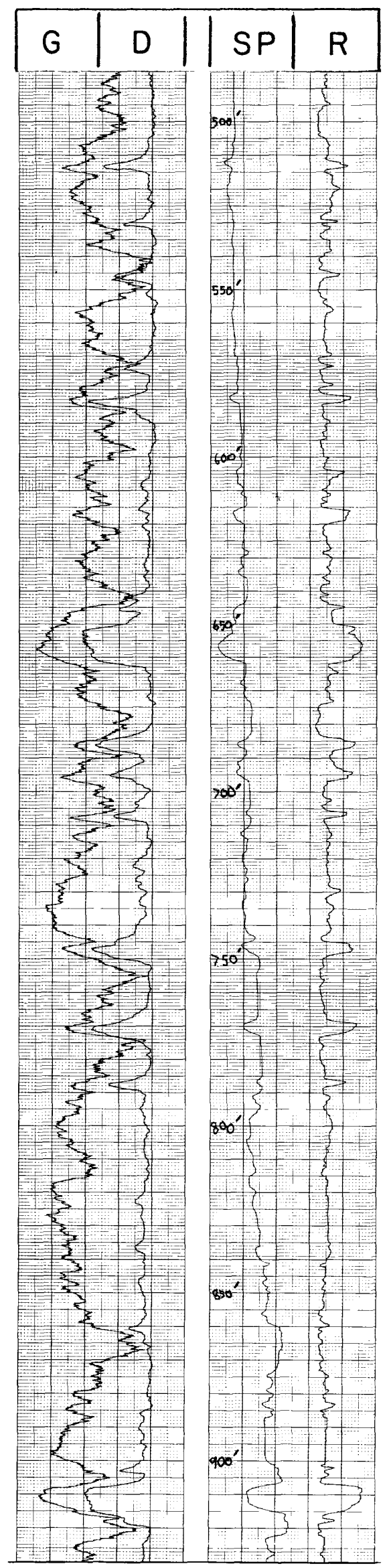

(continued)

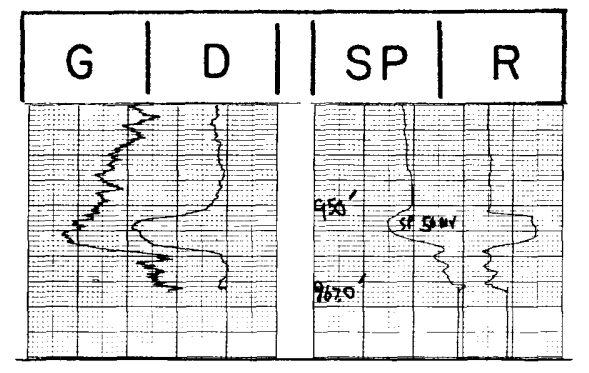


U. S. GEOLOGICAL SURVEY

GEOPHYSICAL LOG, MOFFAT COUNTY, COLORADO

HORSE GULCH QUADRANGLE

Hole no. R-4-HG Date logged 8/20/77_Ground elevation 6,410'

T. 6 N., R. 93 W., Sec. $23: 3,850^{\prime}$ f $1,4,000^{\prime} \mathrm{s} 1$

Drilling medium foam Drilled depth_1,080' Fluid level 289' (first run)

Logging company Rocky Mtn. Logging speed 20'/min. Logged depth 1,066'

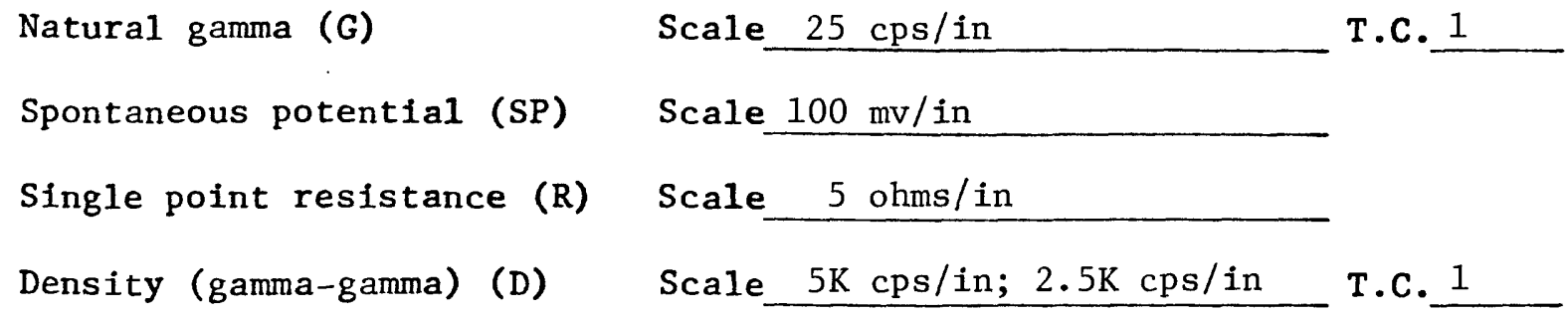

Remarks: Fluid level at $289^{\prime}$ on first run. The density $10 g$ was run to the

surface at $5 \mathrm{~K}$ cps/in. Then an attempt was made to fill the hole with mud, and

the density was rerun, from $289^{\prime}$ up, at $2.5 \mathrm{~K}$ ' cps/in.

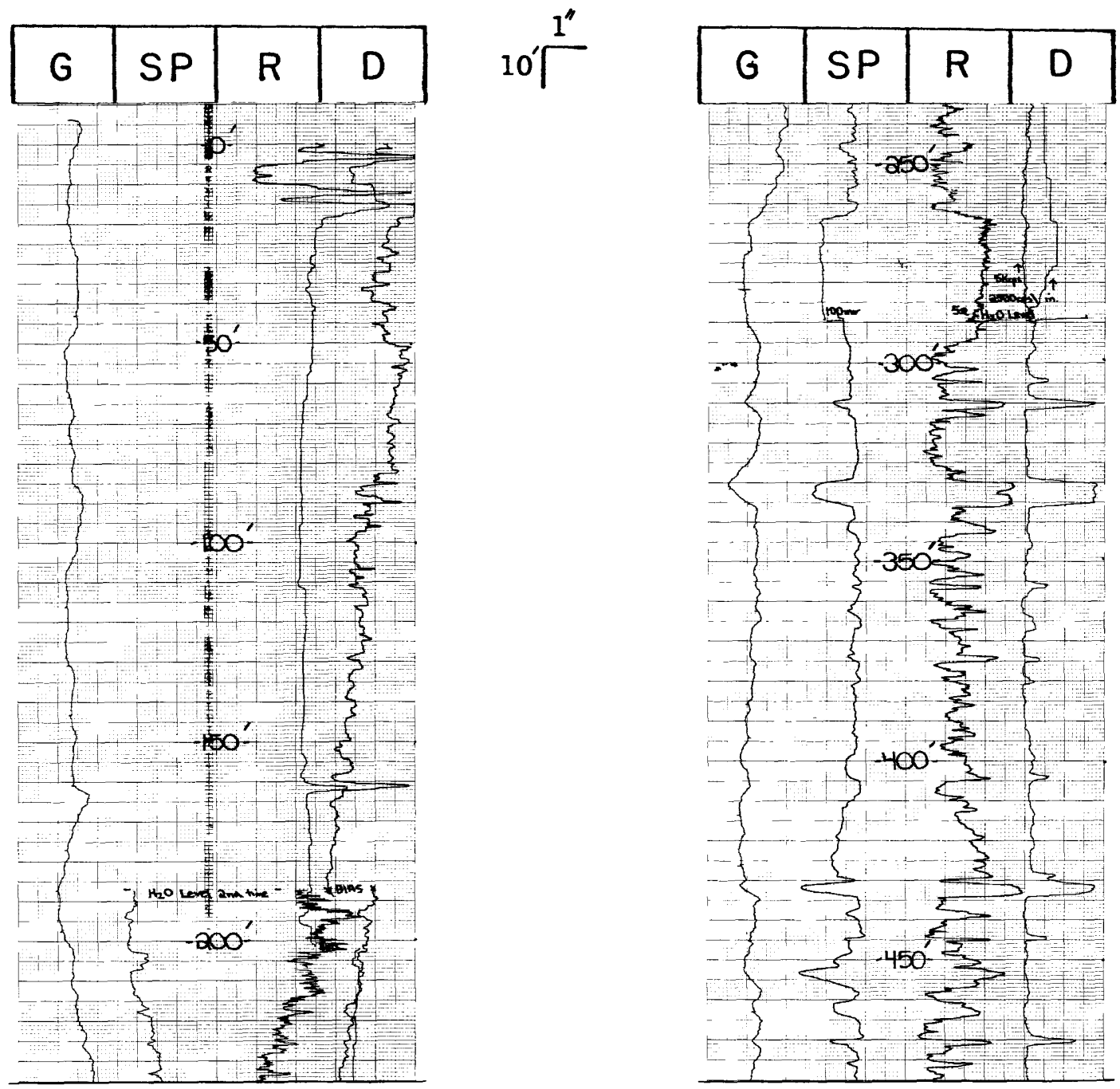


Hole no. R-4-HG

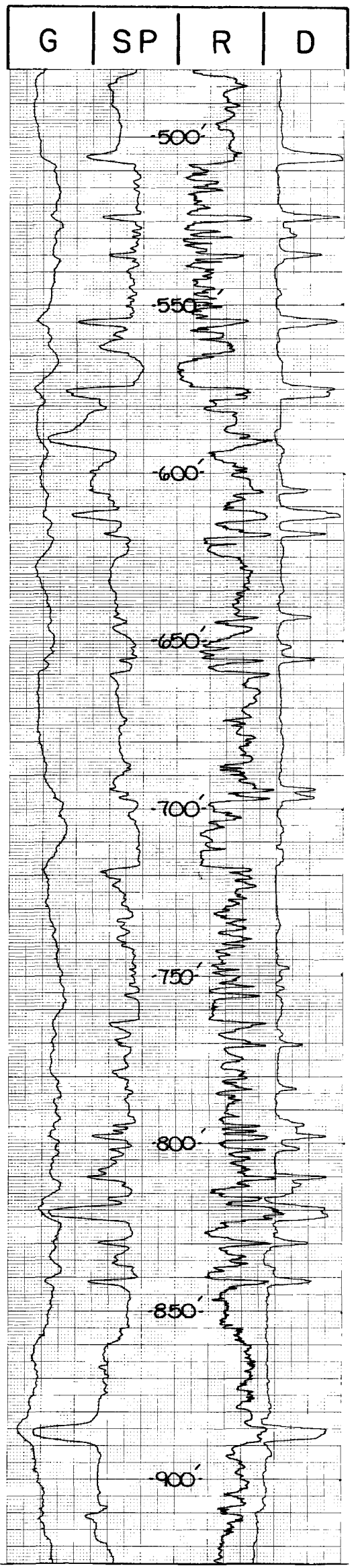

(continued)

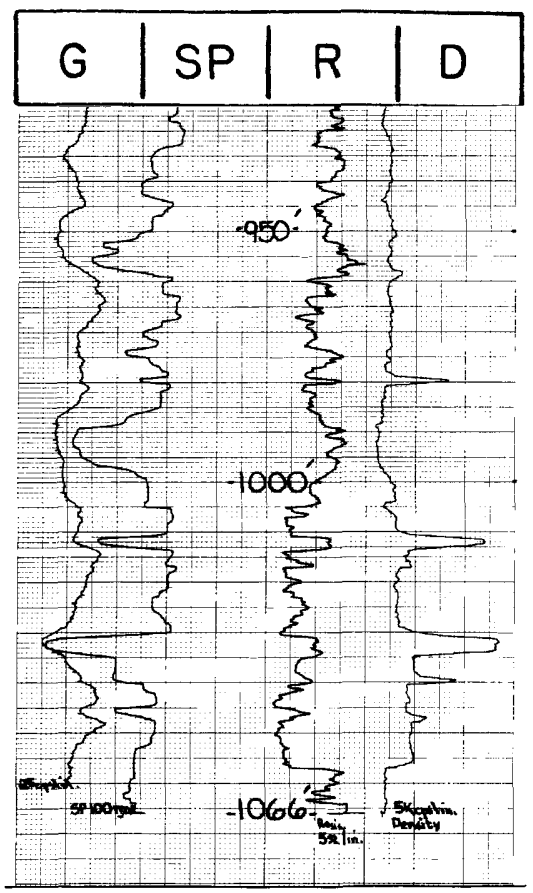


U. S. GEOLOGICAL SURVEY

GEOPHYSICAL LOG, MOFFAT COUNTY, COLORADO

HORSE GULCH QUADRANGLE

Hole no. R-5-HG Date logged 8/22/77_Ground elevation 6,460'

T. 6 N., R. 93 W., Sec. $23:$ 675 f w 1, 1,900'f s 1

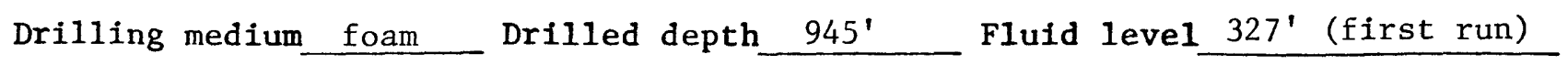

Logging company Rocky Mtn. Logging speed 20'/min. Logged depth 928'

$\begin{array}{llc}\text { Natural gamma (G) } & \text { Scale } 25 \mathrm{cps} / \mathrm{in} & \text { T.C. } 1 \\ \text { Spontaneous potential (SP) } & \text { Scale } 50 \mathrm{mv} / \mathrm{in} ; 100 \mathrm{mv} / \mathrm{in} \\ \text { Single point resistance (R) Scale } 2 \mathrm{ohms} / \mathrm{in} ; 5 \mathrm{ohms} / \mathrm{in} \\ \text { Density (gamma-gamma) (D) Scale_5K cps/in; } 2.5 \mathrm{~K} \mathrm{cps/in} \text { T.C. } 1\end{array}$

Remarks: Spontaneous potential scale changed to $100 \mathrm{mv} / \mathrm{in}$ at $707^{\prime}$. Resistance scale changed to $5 \mathrm{ohms} /$ in at $707^{\prime}$. Density scale changed to $2.5 \mathrm{~K} \mathrm{cps} / \mathrm{in}$ at $327^{\prime}$, the fluid level on the first run. The hole was then filled with a light mud to try to get the SP and $\mathrm{R}$ logs to the surface.

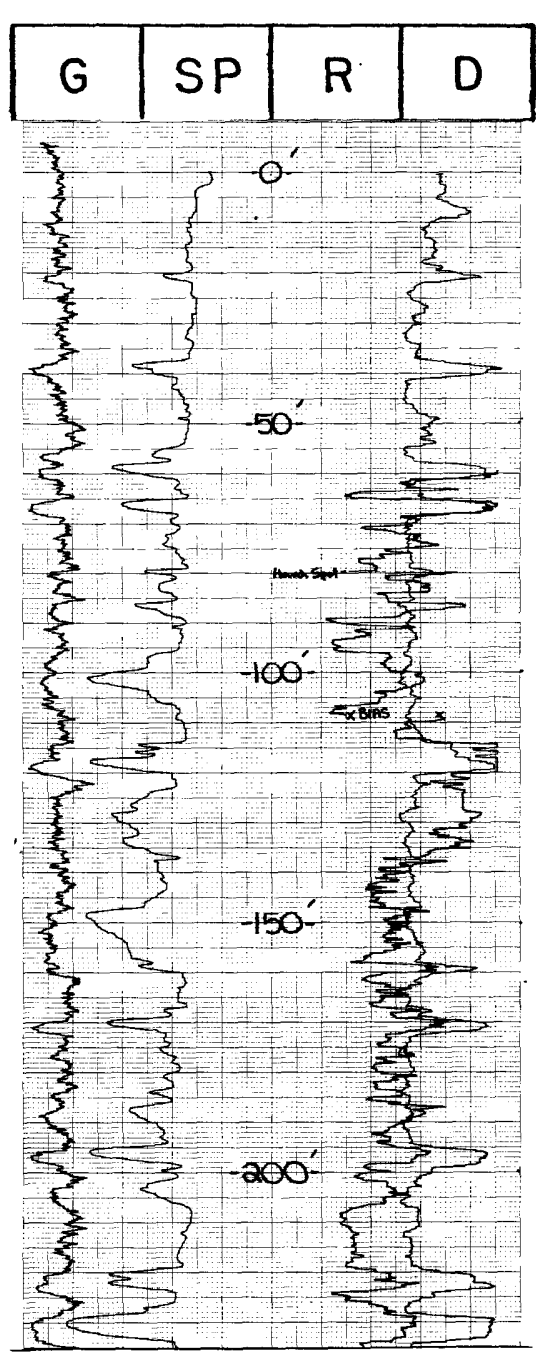

$10^{\prime} \prod^{\prime \prime}$

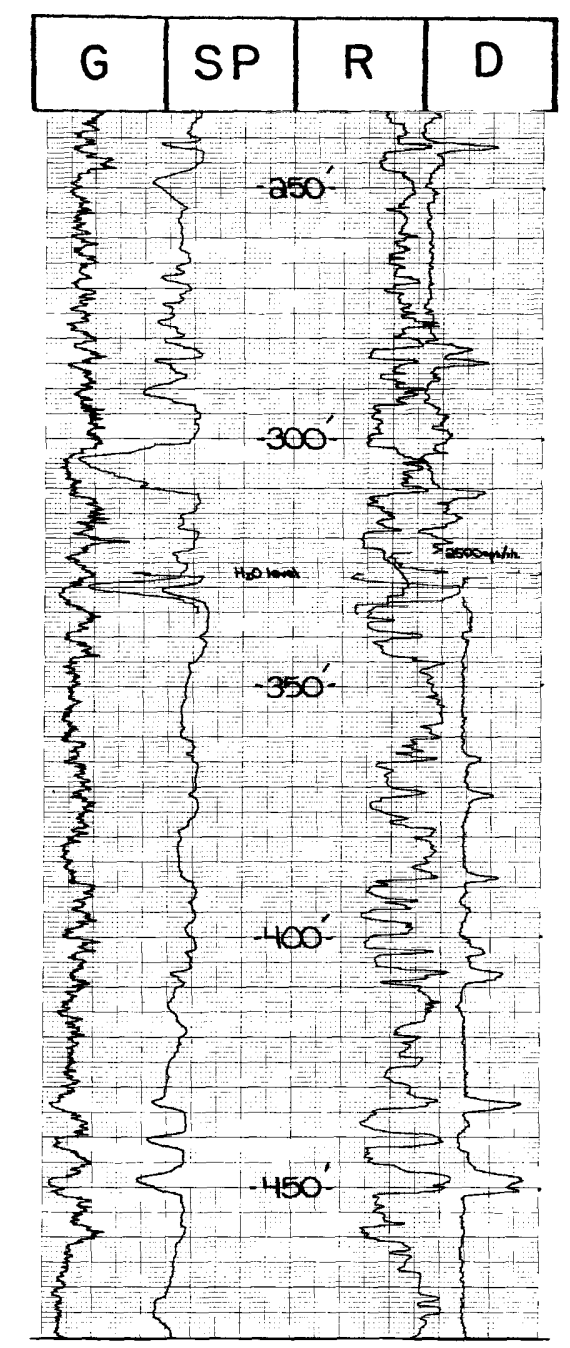


Hole no. R-5-HG

(continued)

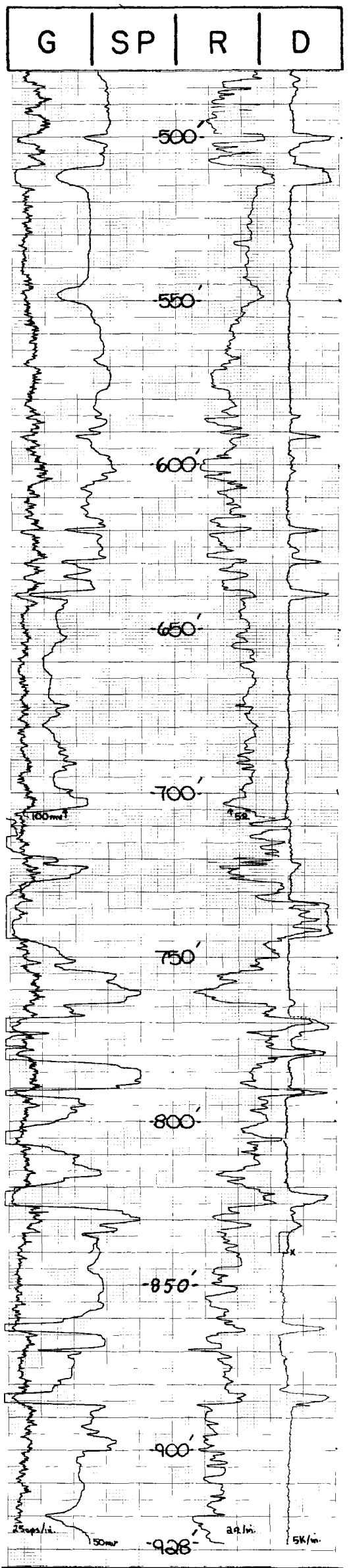

\begin{tabular}{|l|l|l|l|}
\hline$G$ & $S P$ & $R$ & $D$ \\
\hline
\end{tabular} 
U.S. GEOLOGICAL SURVEY

GEOPHYSICAL LOG, MOFFAT COUNTY, COLORADO

HORSE GULCH QUADRANGLE

Hole no. R-6-HG Date logge

$8 / 26 / 77$ Ground elevation 6,615'

T. 6

N., R. 93

W., Sec. $27: 4,490^{\prime}$

f

$1,4,850^{\prime} \mathrm{f}$ s 1

Drilling medium foam

Drilled depth $1,200^{\prime}$

Fluid level $514^{\prime}$ (first run)

Logging company Savage

Logging speed $20 \% / \mathrm{min}$.

Logged depth 1,184'

Natural gamma (G)

Scale $\quad 5 \mathrm{cps} / \mathrm{in}$

T.C. 3

Density (gamma-gamma)

(D)

Scale $100 \mathrm{cps} / \mathrm{in} ; 200 \mathrm{cps} / \mathrm{in}$

T.C. 1

Spontaneous potential (SP)

Scale $20 \mathrm{mv} / \mathrm{in}$

Single point resistance $(R)$ Scale $50 \mathrm{ohms} /$ in

Remarks: Density scale changed to $200 \mathrm{cps} /$ in at $475^{\prime}$. Natural gamma was run a second time, from $505^{\prime}$ to the surface, with a different tool. After the first run, the hole was filled with a light mud to try to get the SP and $R$ logs to the surface.
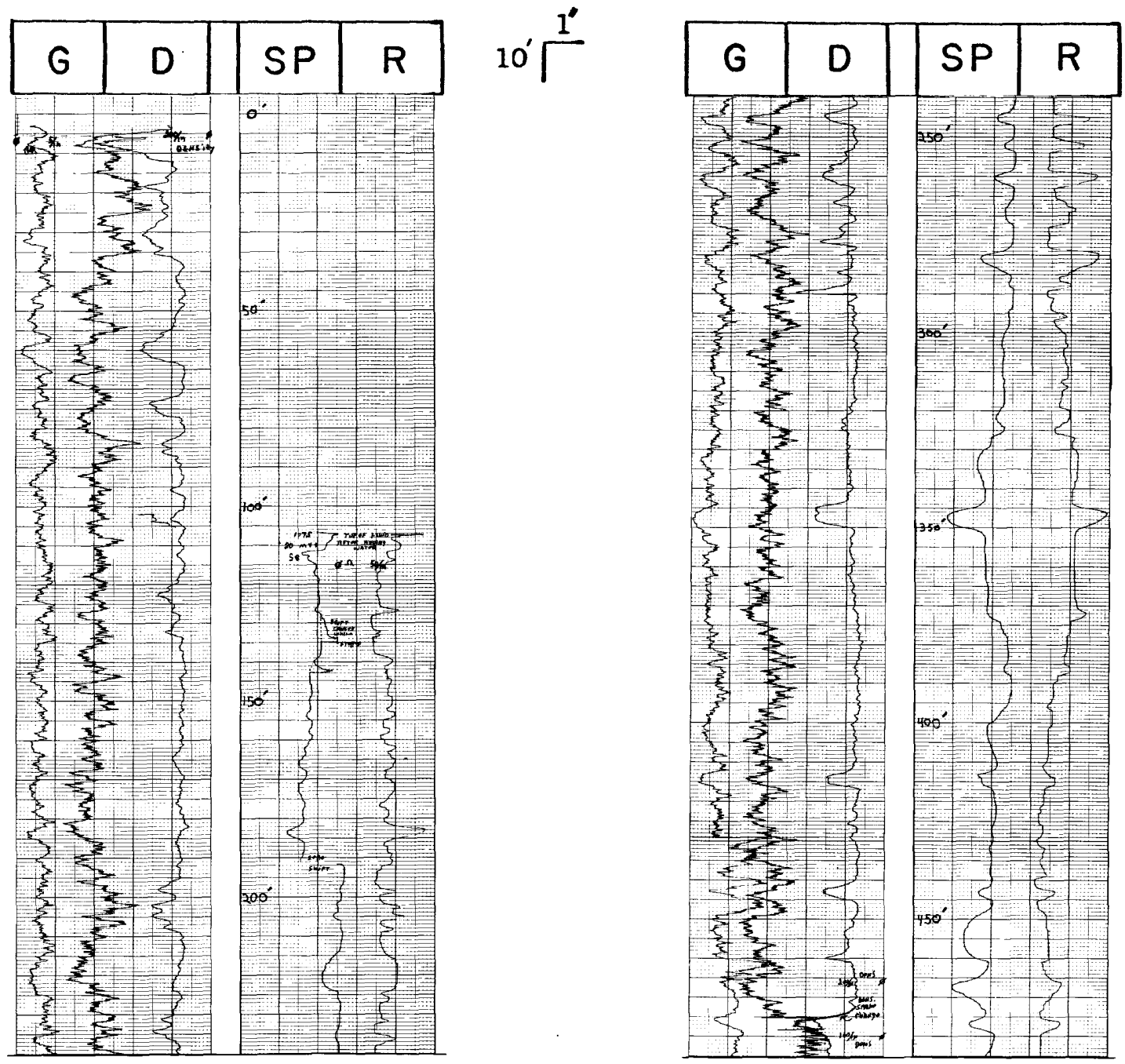
Hole no. R-6-HG (continued)
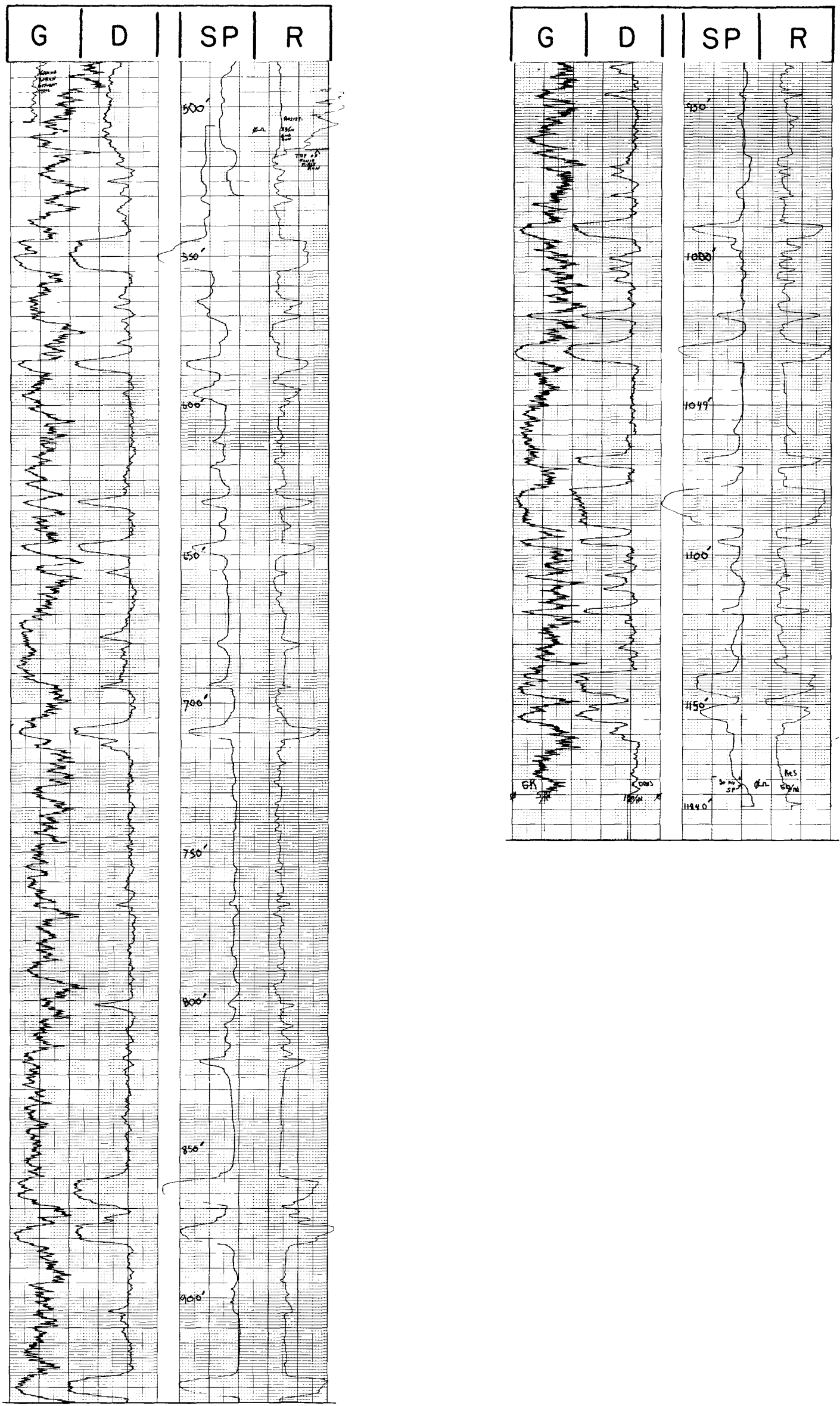
U. S. GEOLOGICAL SURVEY

GEOPHYSICAL LOG, MOFFAT COUNTY, COLORADO

HORSE GULCH QUADRANGLE

Hole no. R-7-HG Date logged 9/5/77_ Ground elevation 6,370'

T. 6 N., R. 93 W., Sec. $26: 3,210^{\prime}$ f $\mathrm{w} 1,3,700^{\prime} \mathrm{f} 1$

Drilling medium foam Drilled depth 1,220'_ Fluid level 13' (after 2 fills wit

Logging company_ Rocky Mtn. Logging speed_20'/min Logged depth 1,183'

$\begin{array}{llc}\text { Natural gamma (G) } & \text { Scale } 25 \mathrm{cps} / \mathrm{in} & \text { T.C. } 1 \\ \text { Spontaneous potential (SP) } & \text { Scale } 5 \mathrm{mv} / \mathrm{in} \\ \text { Single point resistance (R) Scale } 10 \mathrm{ohms} / \mathrm{in} ; 25 \mathrm{ohms} / \mathrm{in} \\ \text { Density (gamma-gamma) (D) } & \text { Scale } 5 \mathrm{~K} \mathrm{cps/in} & \text { T.C. } 1\end{array}$

Remarks: Resistance scale changed to $25 \mathrm{ohms} / \mathrm{in}$ at $530^{\prime}$. At $375^{\prime}$, and again at $87^{\prime}$, the probe was turned off and pulled out of the hole while the upper part of the hole was filled with light mud.

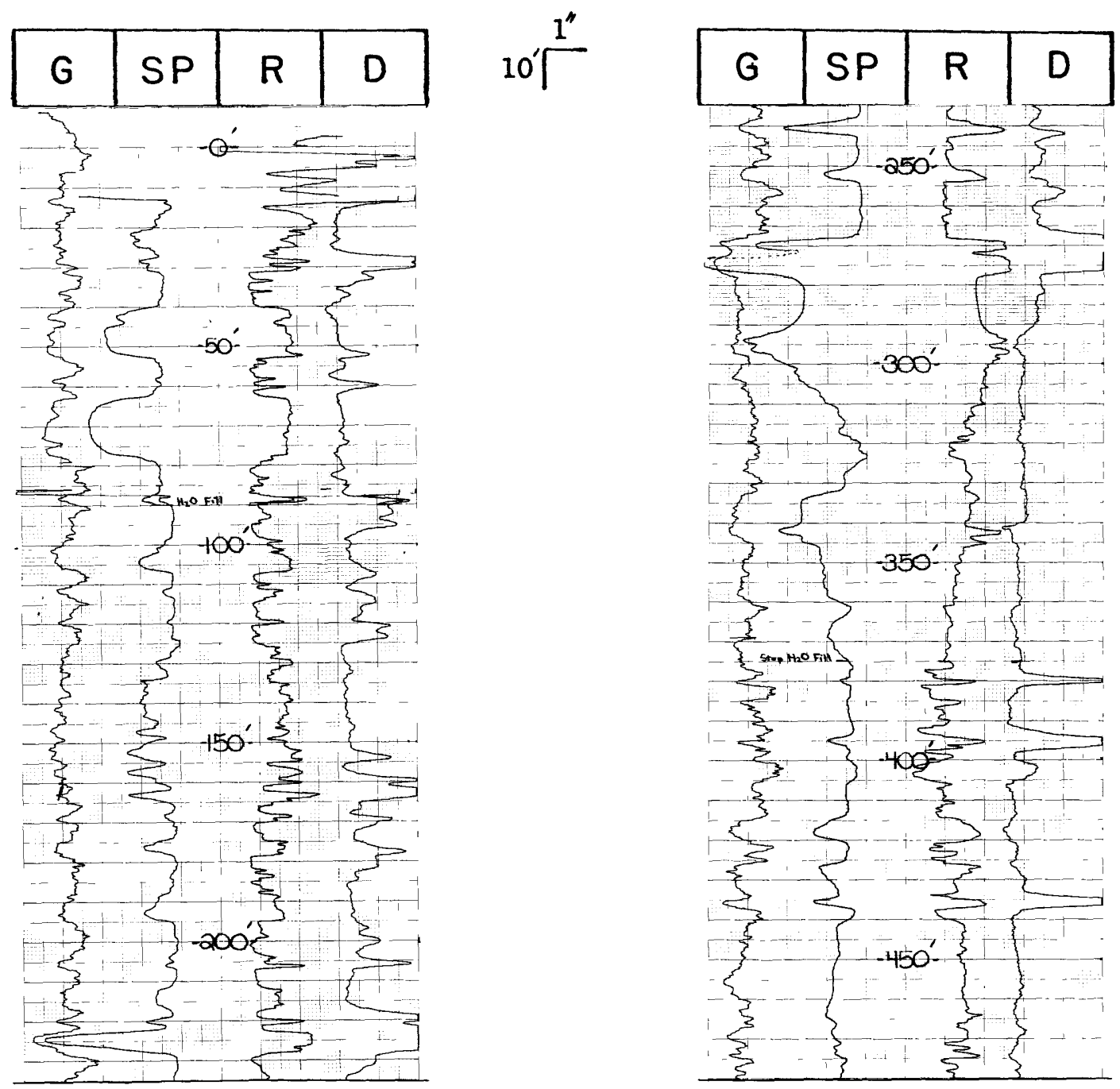


Hole no. R-7-HG



(continued)

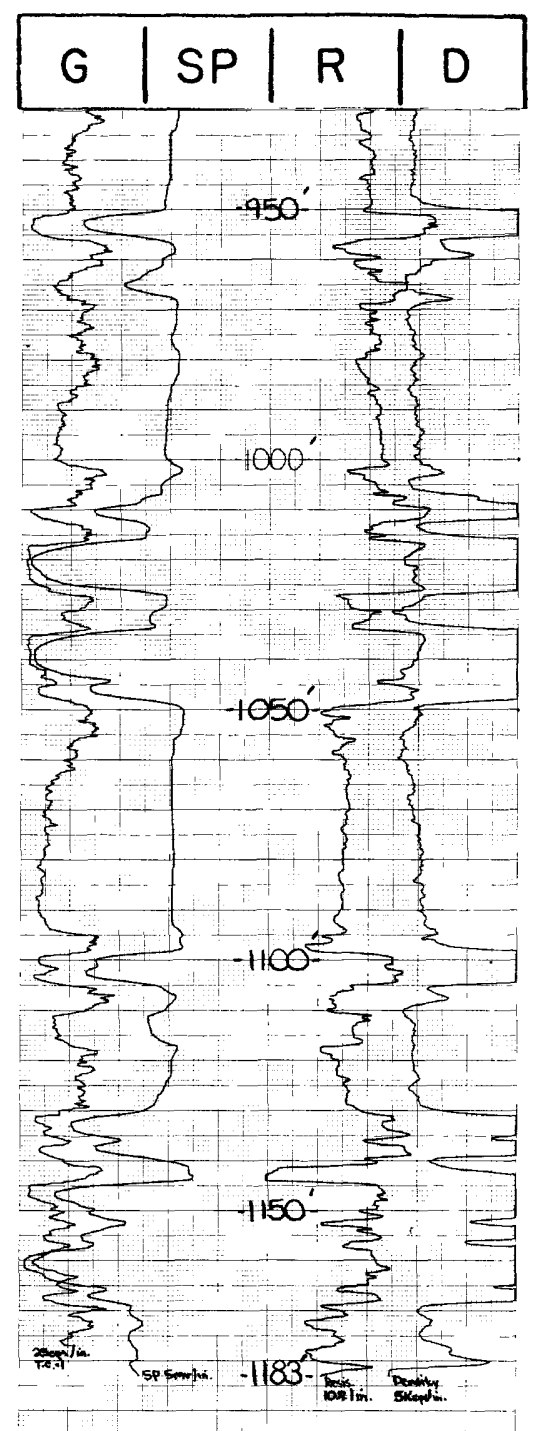


U. S. GEOLOGICAL SURVEY

GEOPHYSICAL LOG, MOFFAT COUNTY, COLORADO

HORSE GULCH QUADRANGLE

Hole no. R-8-HG Date logged 9/10/77_Ground elevation 6,242'

T. 6 N., R. 93 W., Sec. 25: $775^{\prime}$ f w 1, 2,650'f w 1

Drilling medium mud Drilled depth 1,305' Fluid level_ surface

Logging company_Rocky Mtn. Logging speed 20'/min. Logged depth 1,256'

$\begin{array}{llll}\text { Natural gamma (G) } & \text { Scale } 25 \mathrm{cps} / \mathrm{in} & \text { T.C. } 1 \\ \text { Spontaneous potential (SP) } & \text { Scale } 5 \mathrm{mv} / \mathrm{in} \\ \text { Single point resistance (R) Scale } 10 \mathrm{ohms} / \mathrm{in} \\ \text { Density (gamma-gamma) (D) Scale 5K cps/in }\end{array}$

Remarks: None

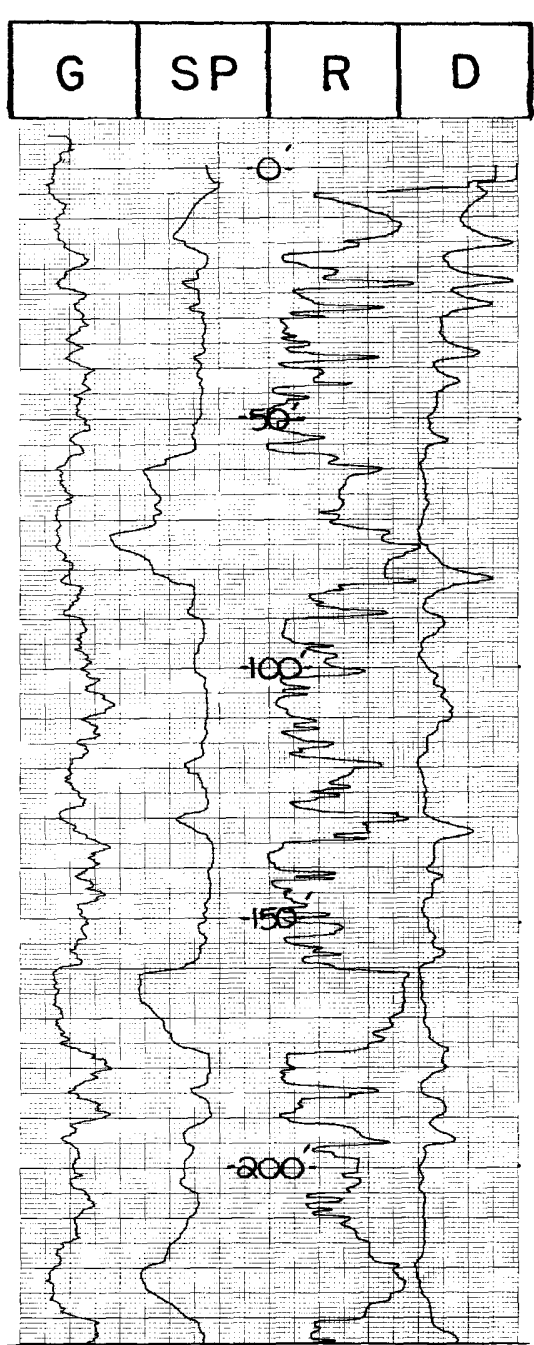

$10^{\prime} \prod^{\prime \prime}$

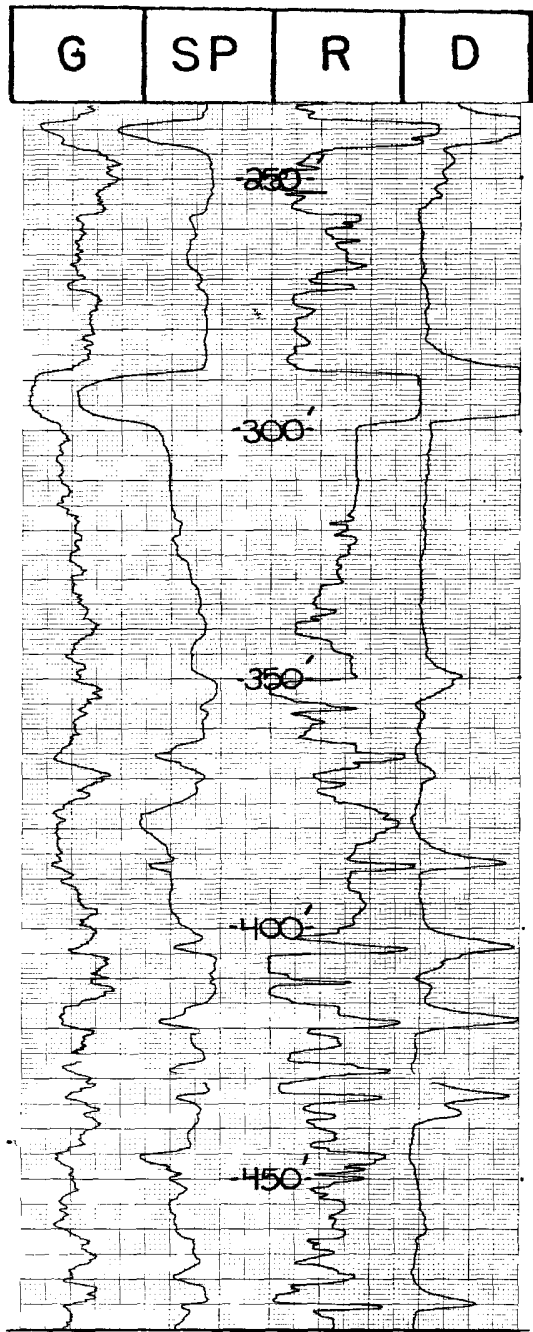


Hole no. R-8-HG

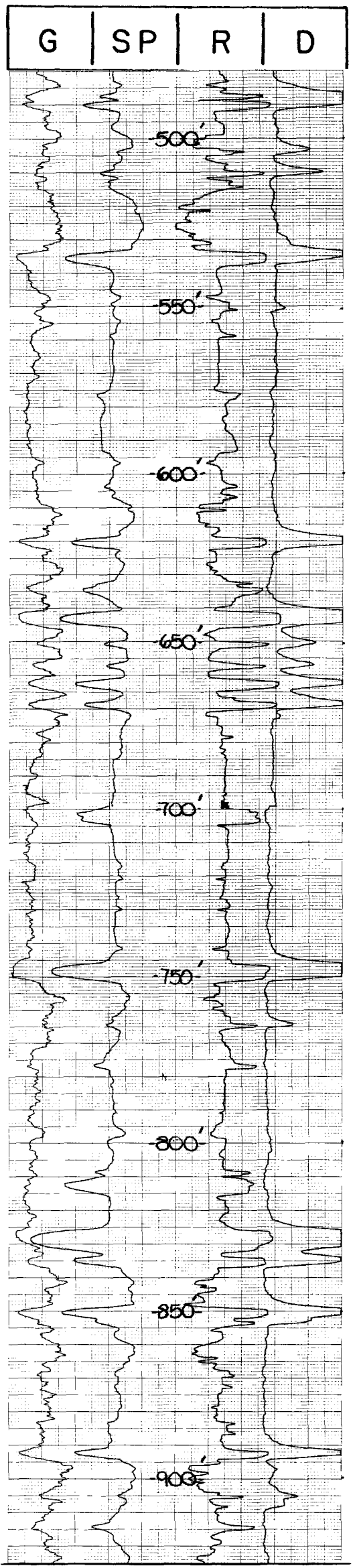

(continued)

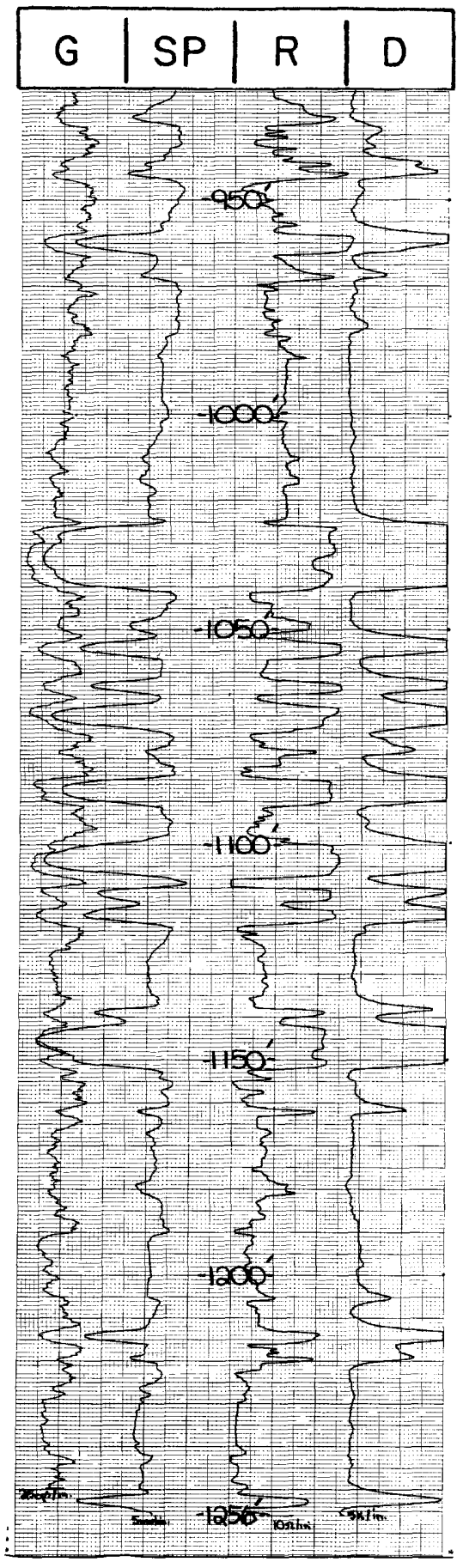


U. S. GEOLOGICAL SURVEY

GEOPHYSICAL LOG, MOFFAT COUNTY, COLORADO

HORSE GULCH QUADRANGLE

Hole no._R-9-HG Date logged 10/4/77_Ground elevation 6,438'

T. 6 N., R. 93 W., Sec. $25: 5,050^{\prime}$ f $\quad 1,4,240^{\prime}$ f $\mathrm{s} I$

Drilling medium mud Drilled depth $1,106^{\prime}$ Fluid level $6^{\prime}$

Logging company Rocky Mtn. Logging speed 20'/min. Logged depth 1,101'

$\begin{array}{lll}\text { Natural gamma (G) } & \text { Scale } 25 \mathrm{cps} / \mathrm{in} & \text { T.C. } \\ \text { Spontaneous potential (SP) } & \text { Scale } 25 \mathrm{mv} / \mathrm{in} ; 10 \mathrm{mv} / \mathrm{in} \\ \text { Single point resistance (R) Scale } 25 \mathrm{ohms} / \mathrm{in} ; 10 \mathrm{ohms} / \mathrm{in} \\ \text { Density (gamma-gamma) (D) Scale } 10 \mathrm{~K} \mathrm{cps/in}\end{array}$

Remarks: Spontaneous potential scale changed to $10 \mathrm{mv} / \mathrm{in}$ at $941^{\prime}$. Resistance scale changed to $10 \mathrm{ohms} /$ in at $900^{\prime}$.

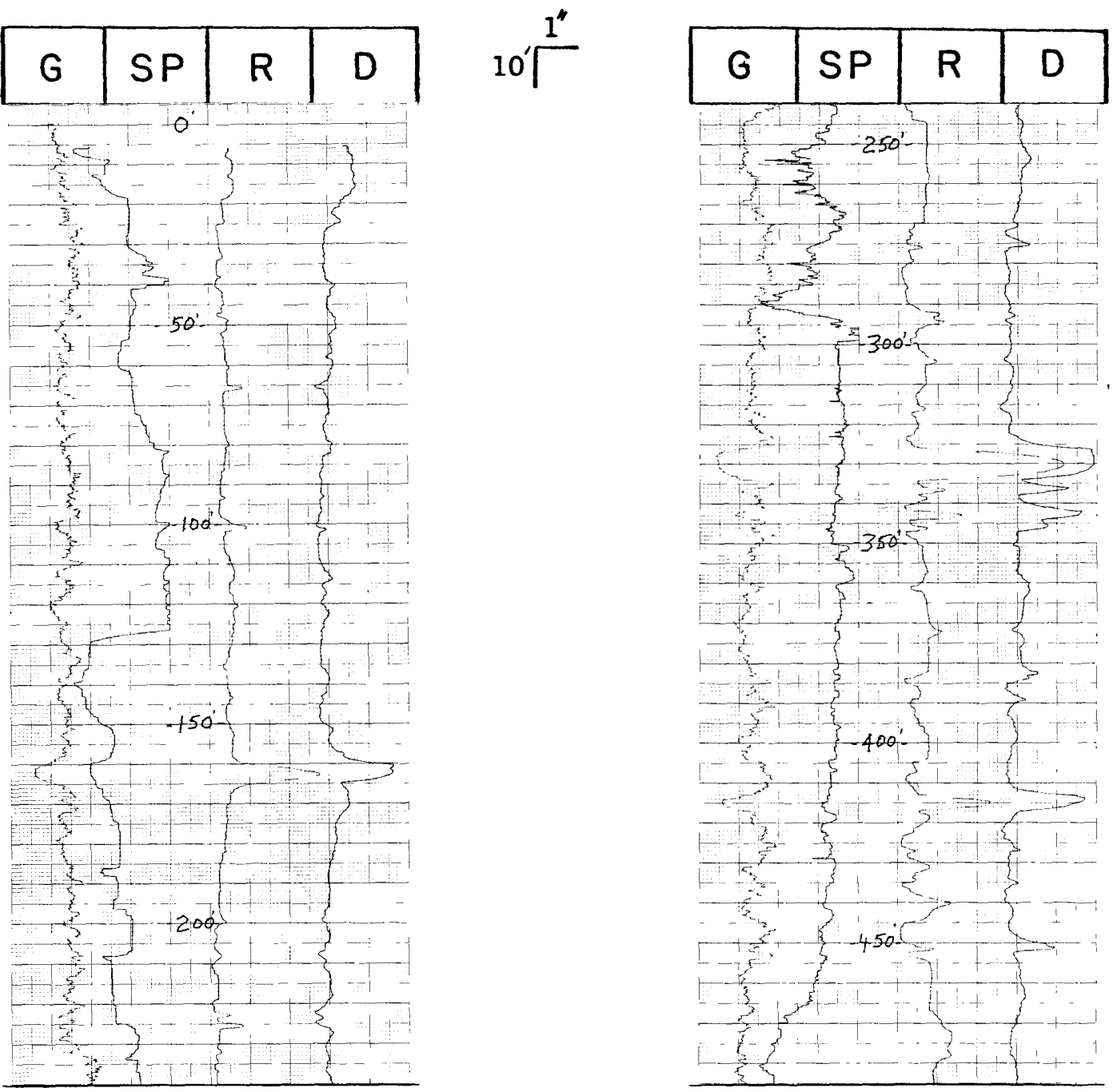


Hole no. R-9-HG
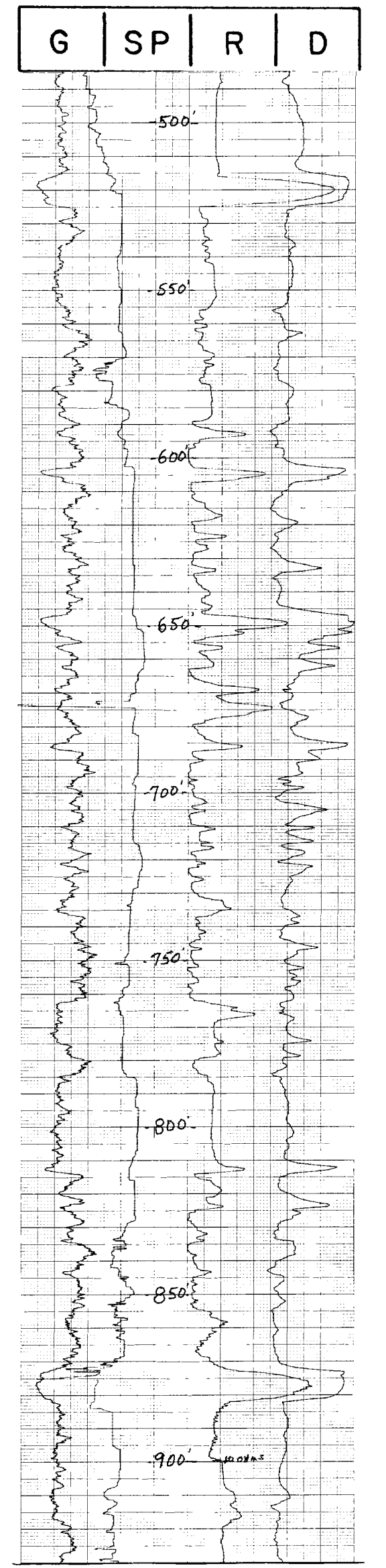

(continued)

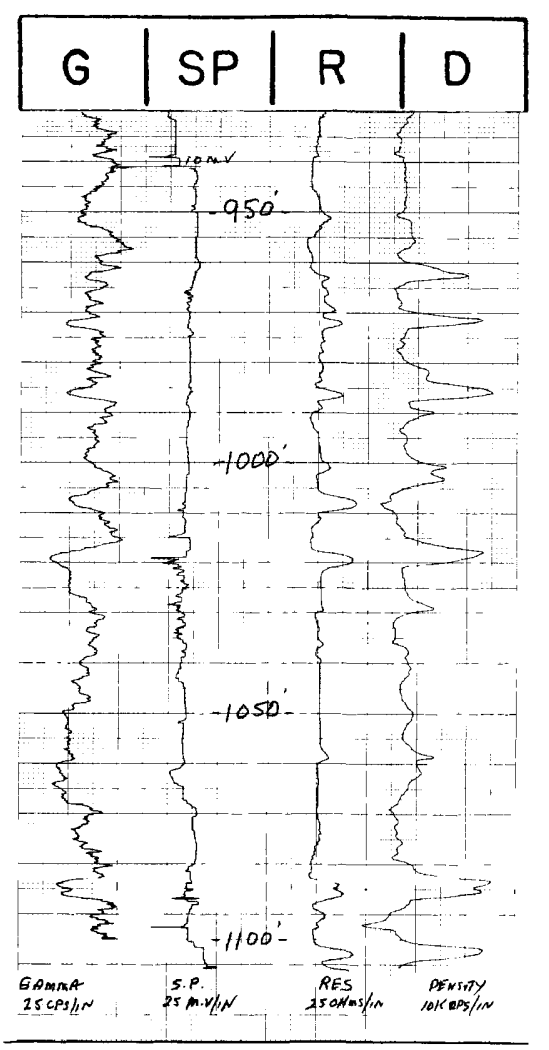


U. S. GEOLOGICAL SURVEY

GEOPHYSICAL LOG, MOFFAT COUNTY, COLORADO

HORSE GULCH QUADRANGLE

Hole no. R-10-HG Date logged $10 / 7 / 77$ Ground elevation $6,420^{\prime}$

T. 6 N., R. 92 W., Sec. 30 : 2,525' f w 1, 2,450'f s 1 Drilling medium mud Drilled depth $1,105^{\prime}$ Fluid level surface

Logging company Digilog

Natural gamma $(G)$

Spontaneous potential (SP)

Single point resistance (R)

Density (gamma-gamma)

(D)
Logging speed $20^{\prime} / \mathrm{min}$.

Logged depth 1,102'

Scale $20 \mathrm{cps} / \mathrm{in}$

T.C. 2

Scale $20 \mathrm{mv} / \mathrm{in}$

Scale 10 ohms/in

Scale $60 \mathrm{cps} / \mathrm{in}$

T.C. 0.5

Remarks: None

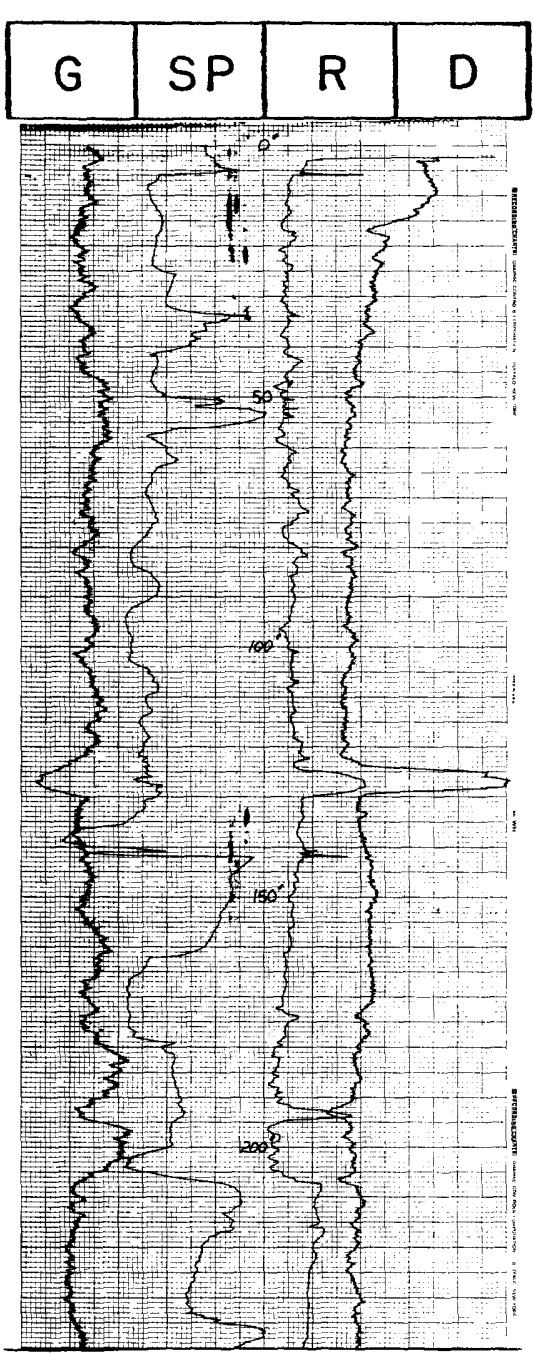

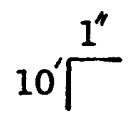

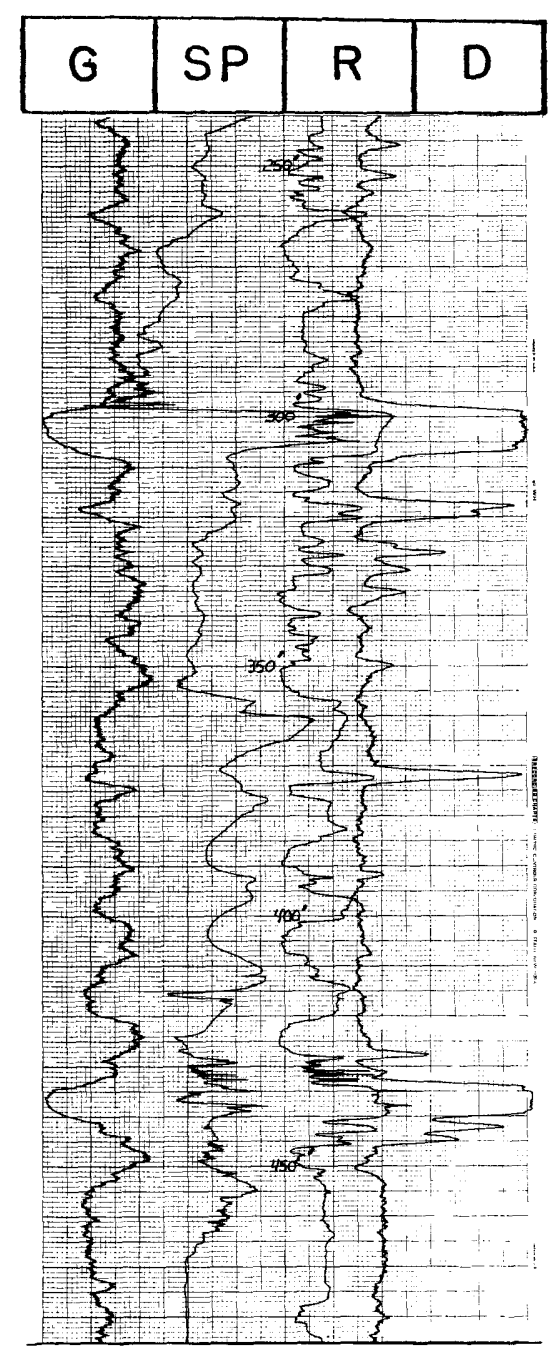


Hole no. R-10-HG

(continued)
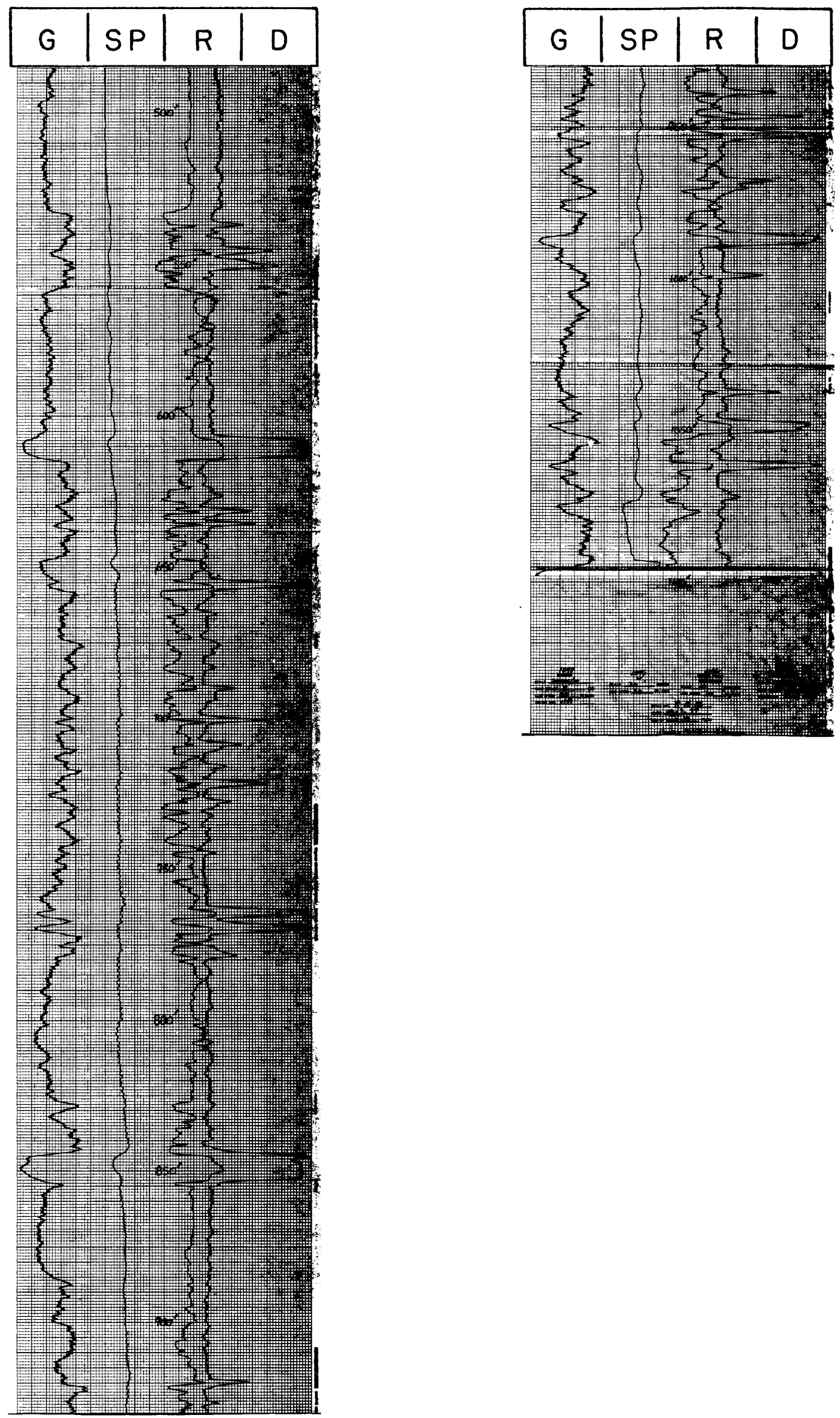
U. S. GEOLOGICAL SURVEY

GEOPHYSICAL LOG, MOFFAT COUNTY, COLORADO

HORSE GULCH QUADRANGLE

Hole no. R-11-HG Date logged $10 / 2 / 77$ Ground elevation $6,355^{\prime}$

T. 6 N., R. 92 W., Sec. 31: 2,725' f w $1,3,725^{\prime}$ f s 1

Driliing medium mud Drilled depth 1,505' Fluid level 4'

Logging company Rocky Mtn. Logging speed $10^{\prime} / \mathrm{min}$. Logged depth 1,501'

\begin{tabular}{lll} 
Natural gamma (G) & Scale $10 \mathrm{cps} / \mathrm{in} ; 25 \mathrm{cps} / \mathrm{in}$ & T.C. 1 \\
Spontaneous potential (SP) & Scale $10 \mathrm{mv} / \mathrm{in}$ \\
Single point resistance (R) Scale $10 \mathrm{ohms} / \mathrm{in}$ \\
Density (gamma-gamma) (D) & Scale $10 \mathrm{~K} \mathrm{cps} / \mathrm{in}$ & T.C. 1 \\
\hline
\end{tabular}

Remarks: Natural gamma scale changed to $25 \mathrm{cps} /$ in at $306^{\prime}$.

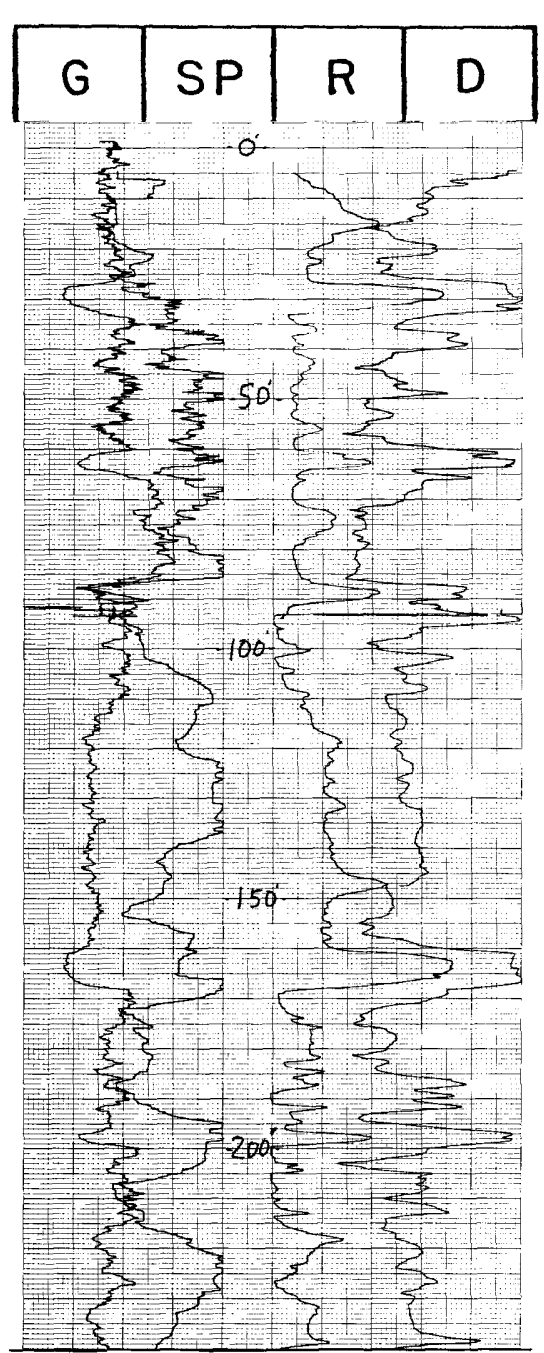

$10^{\prime} T^{\prime \prime}$

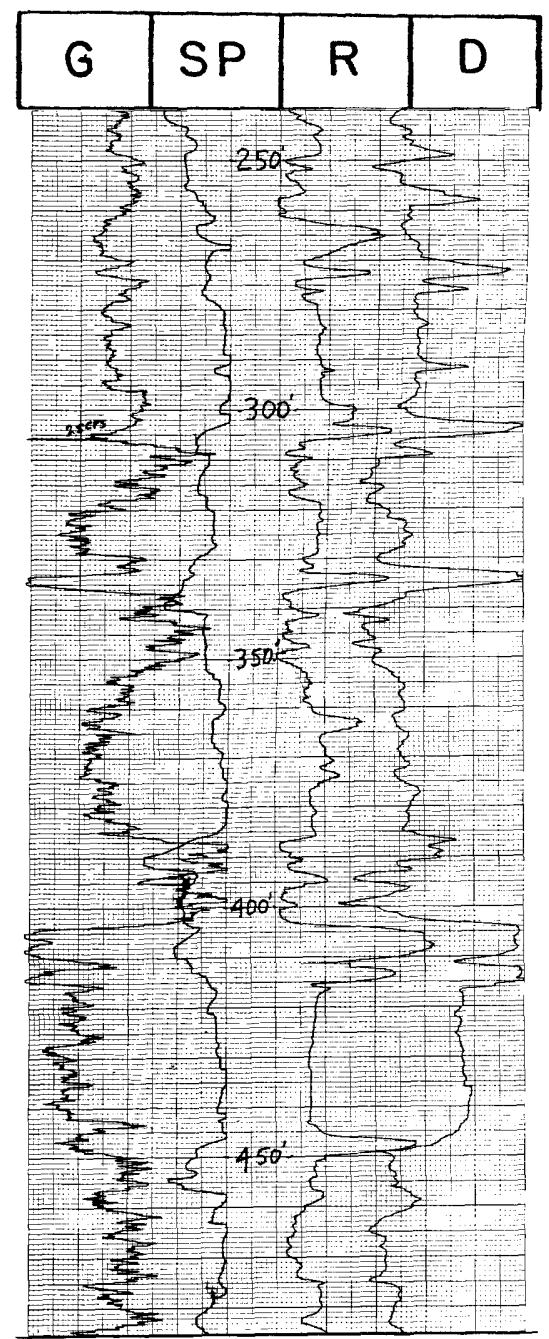


Hole no. R-11-HG

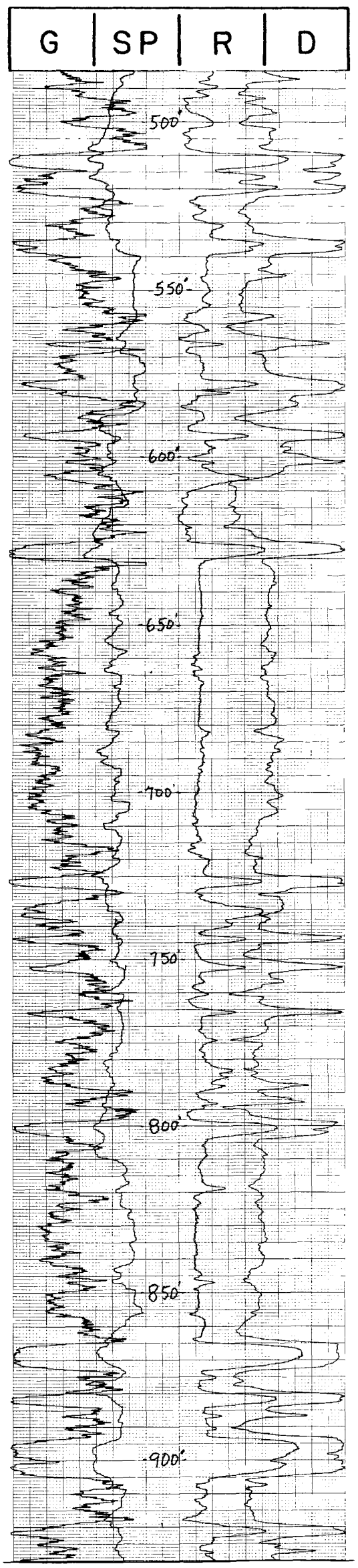

(continued)

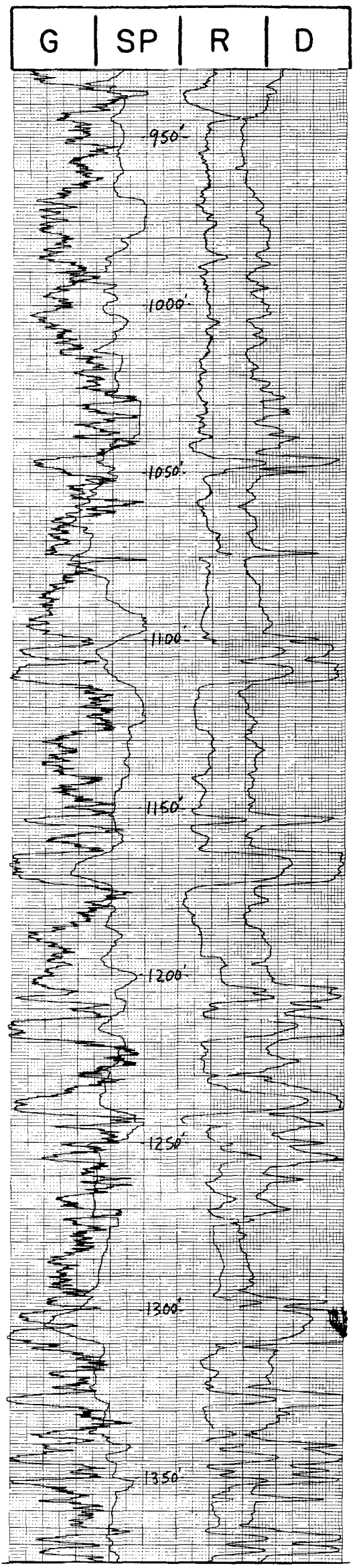


U. S. GEOLOGICAL SURVEY

GEOPHYSICAL LOG, MOFFAT COUNTY, COLORADO

HORSE GULCH QUADRANGLE

Hole no. R-12-HG Date logged 9/20/77_Ground elevation 6,518'

T. 6 N., R. 92 W., Sec. 31 : $125^{\prime}$ f w $1,2,400^{\prime}$ f s 1

Drilling medium foam Drilled depth 1,286'_Fluid level 444' (first run)

Logging company Rocky Mtn. Logging speed 20'/min. Logged depth 1,286'

$\begin{array}{lll}\text { Natural gamma (G) } & \text { Scale } 25 \mathrm{cps} / \mathrm{in} & \text { T.C. } \\ \text { Spontaneous potential (SP) } & \text { Scale } 100 \mathrm{mv} / \mathrm{in} \\ \text { Single point resistance (R) Scale } 10 \mathrm{ohms} / \mathrm{in} ; 5 \mathrm{ohms} / \mathrm{in} \\ \text { Density (gamma-gamma) (D) Scale } 5 \mathrm{~K} \mathrm{cps/in;} 10 \mathrm{~K} \mathrm{cps/in} \text { T.C. } 1\end{array}$

Remarks: Three runs were made of the top part of the hole due to two attempts to fill the hole with a light mud. Density scale changed to $10 \mathrm{~K}$ cps/in above fluid level on each run. Resistance scale is $10 \mathrm{ohms} /$ in on first run, 5 ohms/in on second and third runs.

Hole no. R-11-HG (continued)

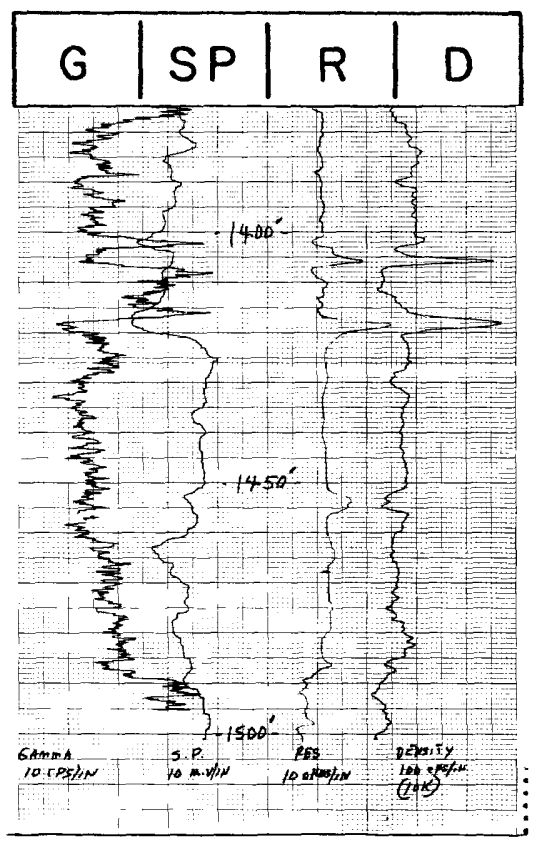

\begin{tabular}{|l|l|l|l|}
\hline$G$ & $S P$ & $R$ & $D$ \\
\hline
\end{tabular}


Hole no. R-12-HG

(continued)
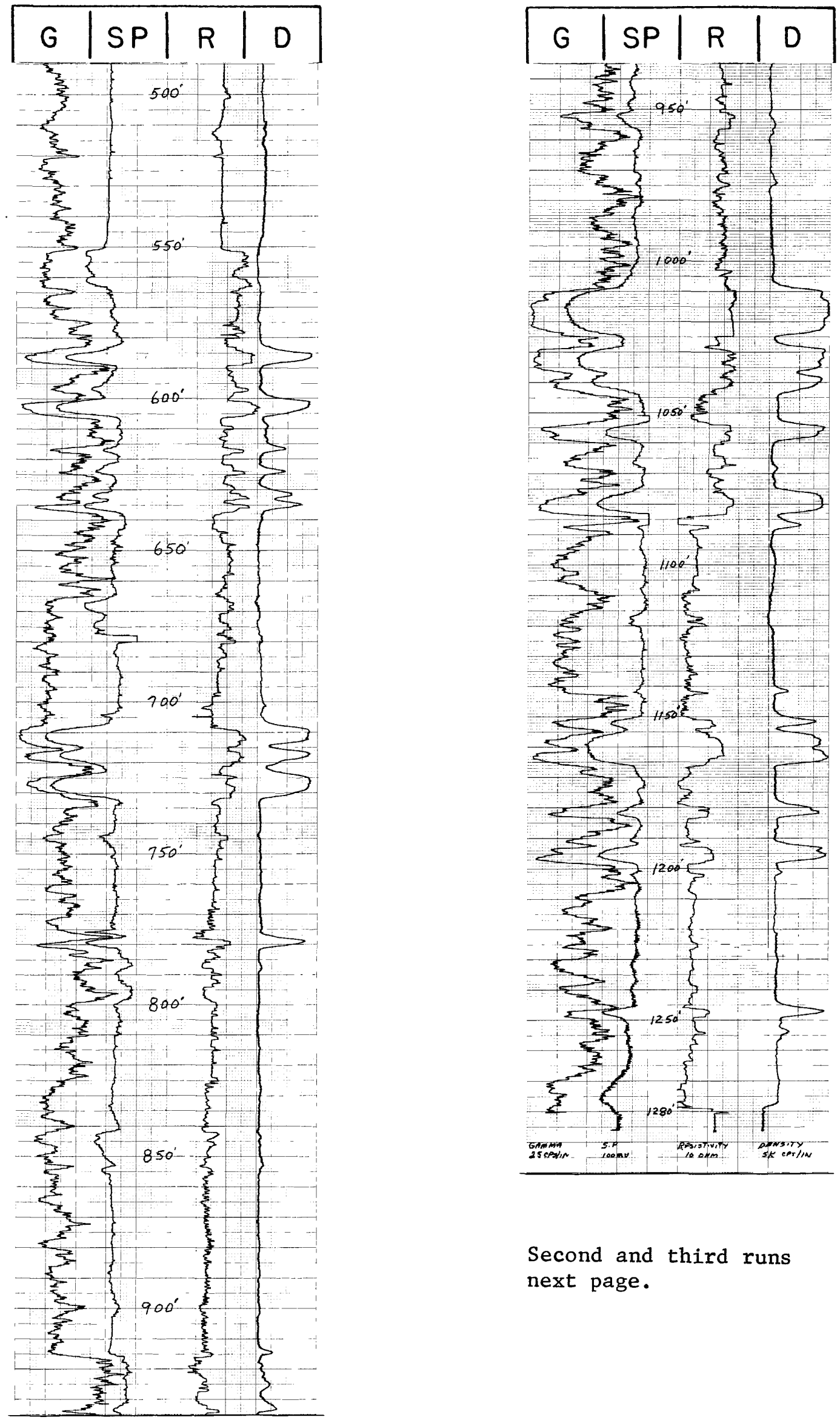

Second and third runs next page. 

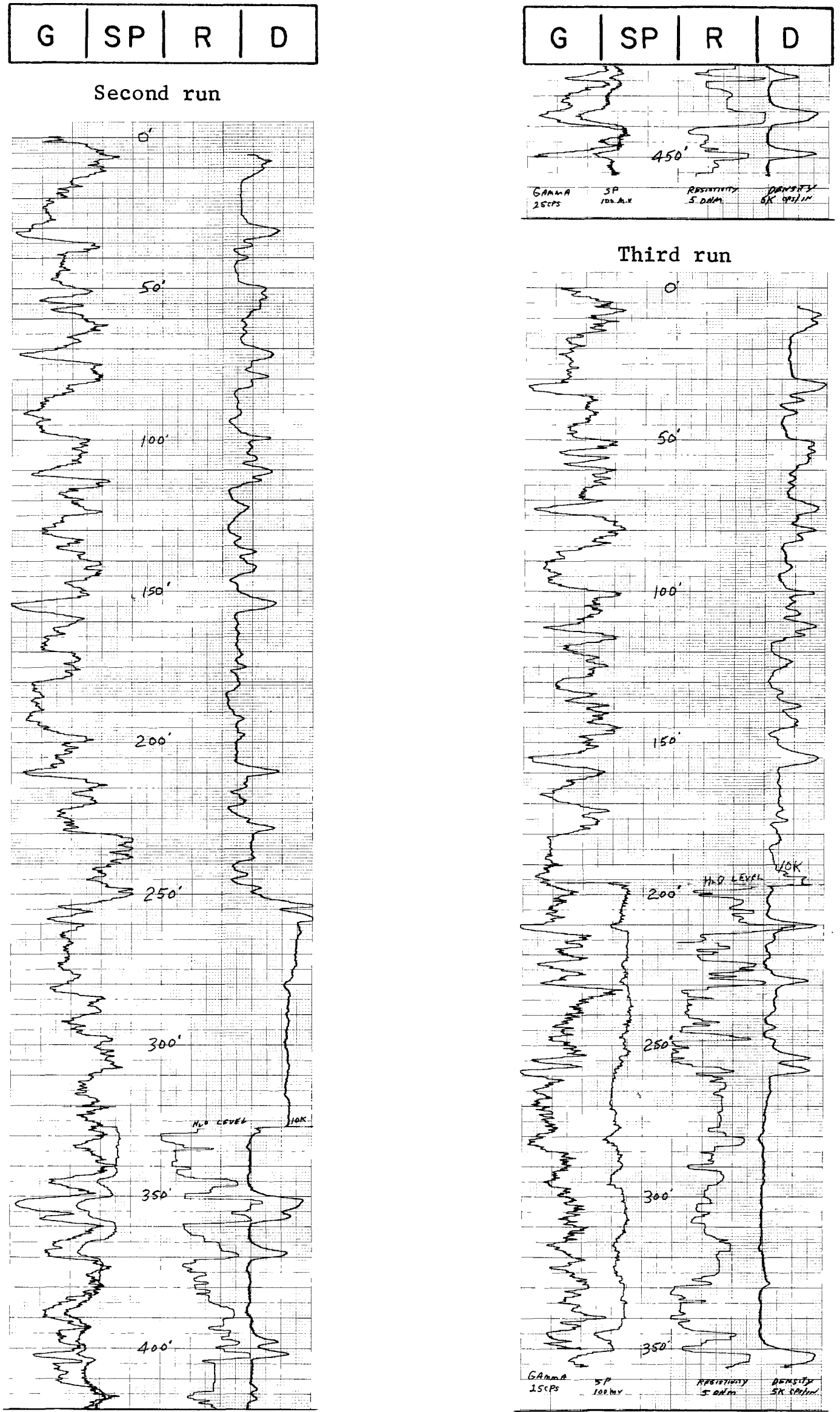

\section{Third run}

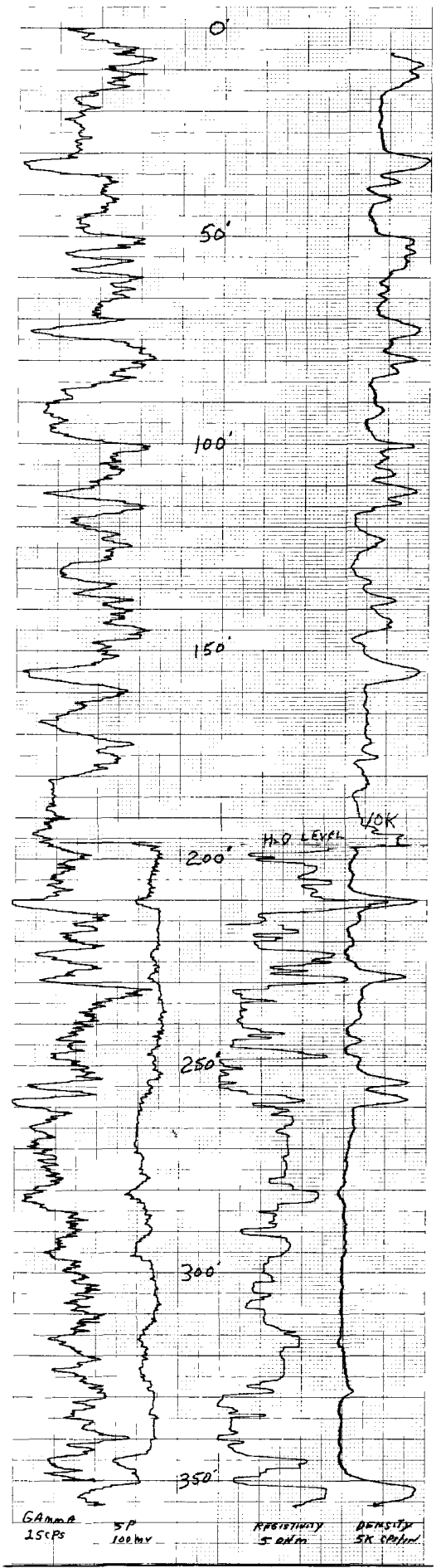


U. S. GEOLOGICAL SURVEY

GEOPHYSICAL LOG, MOFFAT COUNTY, COLORADO

HORSE GULCH QUADRANGLE

Hole no. R-13-HG Date logged 9/22/77_Ground elevation 6,445'

T. 6 N., R. 92 W., Sec. $30:$ 200' f w $1,240^{\prime}$ f $s$

Drilling medium foam Drilled depth 925' Fluid level 225' (first run)

Logging company Rocky Mtn. Logging speed 20'/min. Logged depth 916'

Natural gamma (G)

Spontaneous potential (SP)

Single point resistance (R) Scale $10 \mathrm{ohms} / \mathrm{in}$

Density (gamma-gamma) (D)
Scale $25 \mathrm{cps} /$ in

T.C. 1

Scale $5 \mathrm{~K} \mathrm{cps} / \mathrm{in}$; $10 \mathrm{~K} \mathrm{cps} / \mathrm{in}$ T.c. 1

Remarks: Four runs were made of the top part of the hole due to three attempts to fill the hole with a light mud. Density scale changed to $10 \mathrm{~K} \mathrm{cps} / \mathrm{in}$ above

fluid level on each run. Spontaneous potential scale changed to $25 \mathrm{mv} /$ in on third and fourth runs.

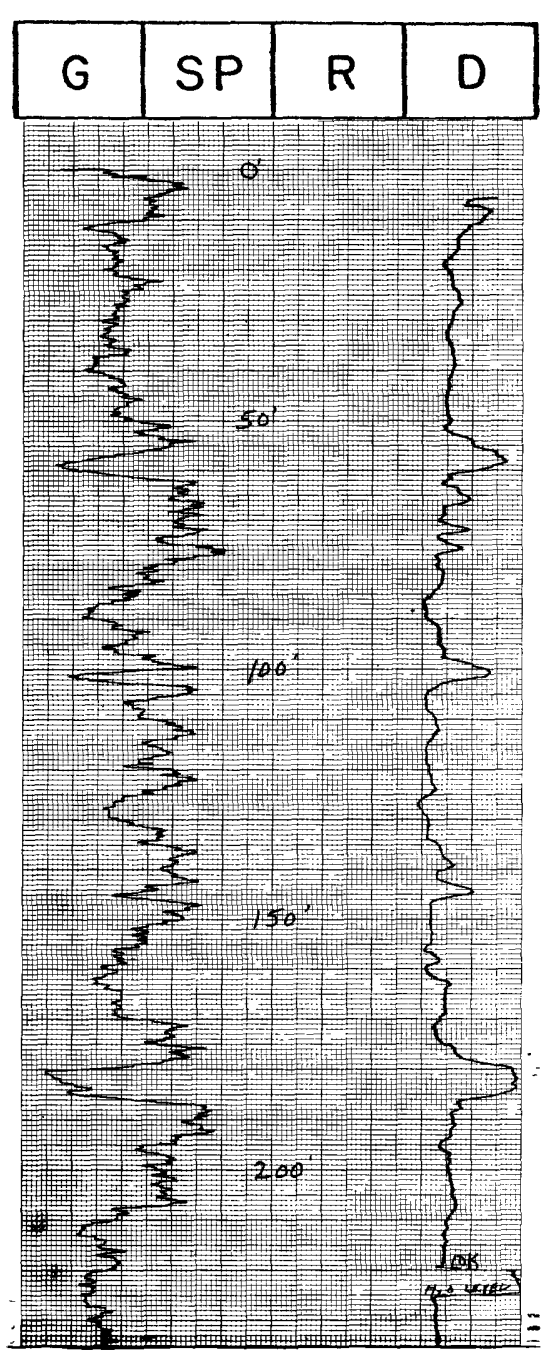

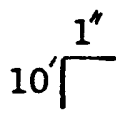

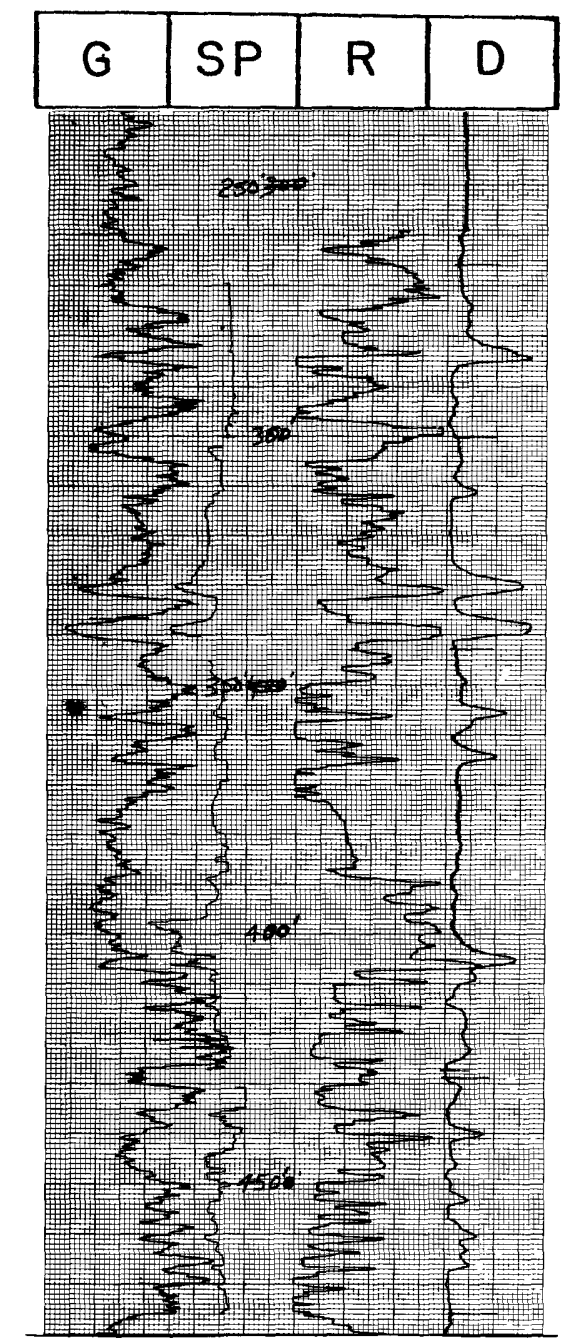


Hole no. R-13-HG

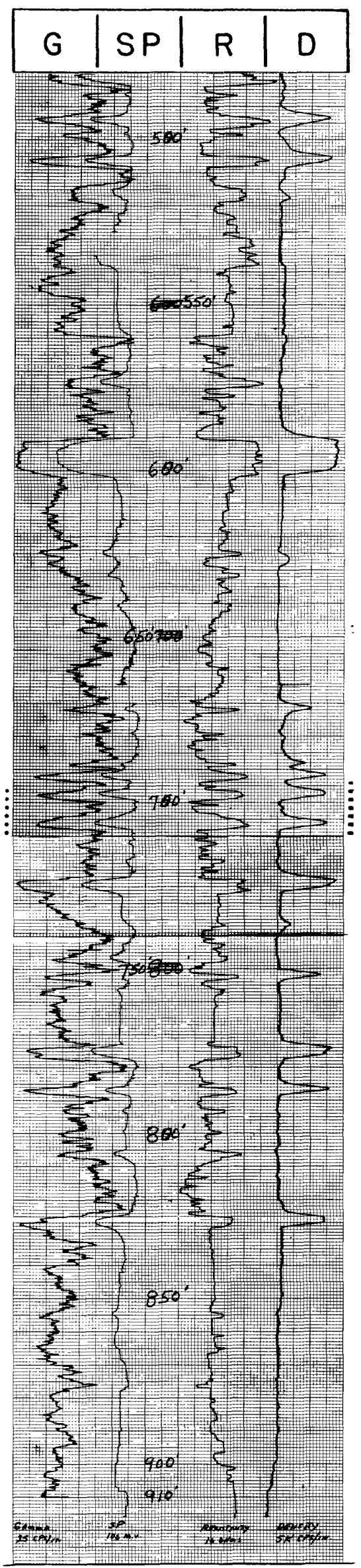

(continued)

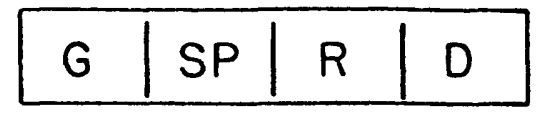

Second run

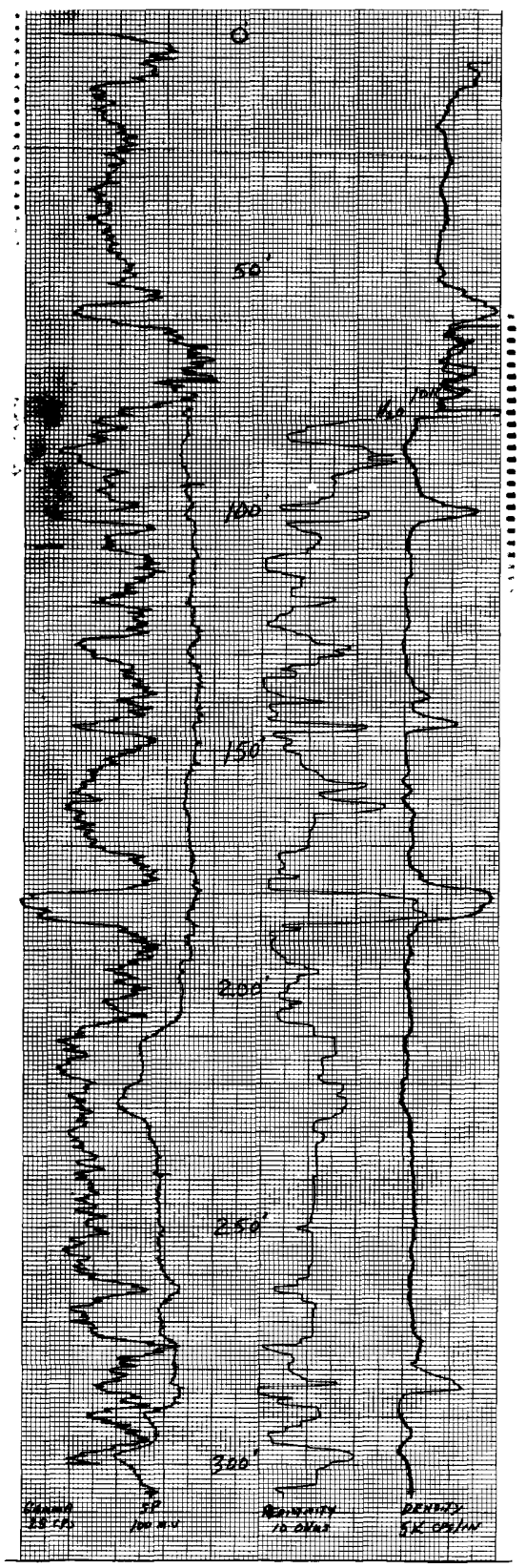

Third and fourth runs next page. 
Hole no. R-13-HG

\begin{tabular}{|l|l|l|l|}
\hline$G$ & $S P$ & $R$ & $D$ \\
\hline
\end{tabular}

Third run

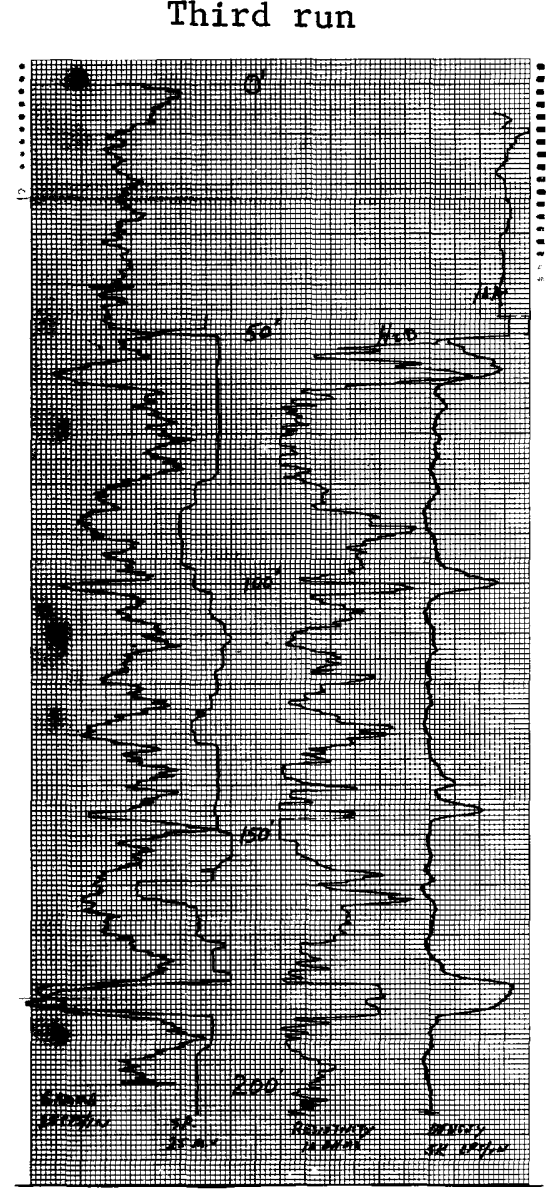

Fourth run

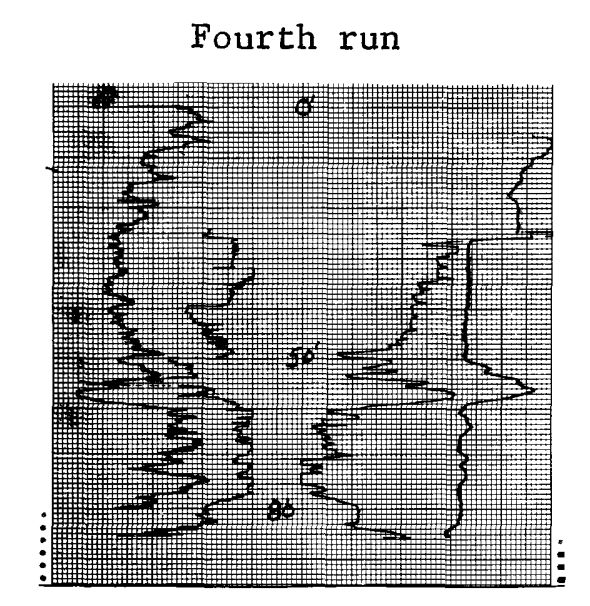

(continued)

\begin{tabular}{|l|l|l|l|}
\hline$G$ & $S P$ & $R$ & $D$ \\
\hline
\end{tabular}


U. S. GEOLOGICAL SURVEY

GEOPHYSICAL LOG, MOFFAT COUNTY, COLORADO

HORSE GULCH QUADRANGLE

Hole no. R-14-HG Date logged 9/17/77_ Ground elevation $6,482^{\prime}$

T. 6 N., R. 93 W., Sec. 26 : 5,110' f w $1,260^{\prime}$ f s 1

Drilling medium foam Drilled depth 880'_ Fluid level 410'

Logging company Rocky Mtn. Logging speed 20'/min. Logged depth $877^{\prime}$

$\begin{array}{llcl}\text { Natural gamma (G) } & \text { Scale } & 25 \mathrm{cps} / \mathrm{in} & \text { T.C. } \\ \text { Spontaneous potential (SP) } & \text { Scale } & 100 \mathrm{mv} / \mathrm{in} \\ \text { Single point resistance (R) } & \text { Scale } & 10 \mathrm{ohms} / \mathrm{in} \\ \text { Density (gamma-gamma) (D) } & \text { Scale } & 5 \mathrm{~K} \mathrm{cps} / \mathrm{in} & \text { T.C. } 1\end{array}$

Remarks: Hole drilled "blind" (i.e. no return of cuttings to the surface) from $395^{\prime}$ to $880^{\prime}$.

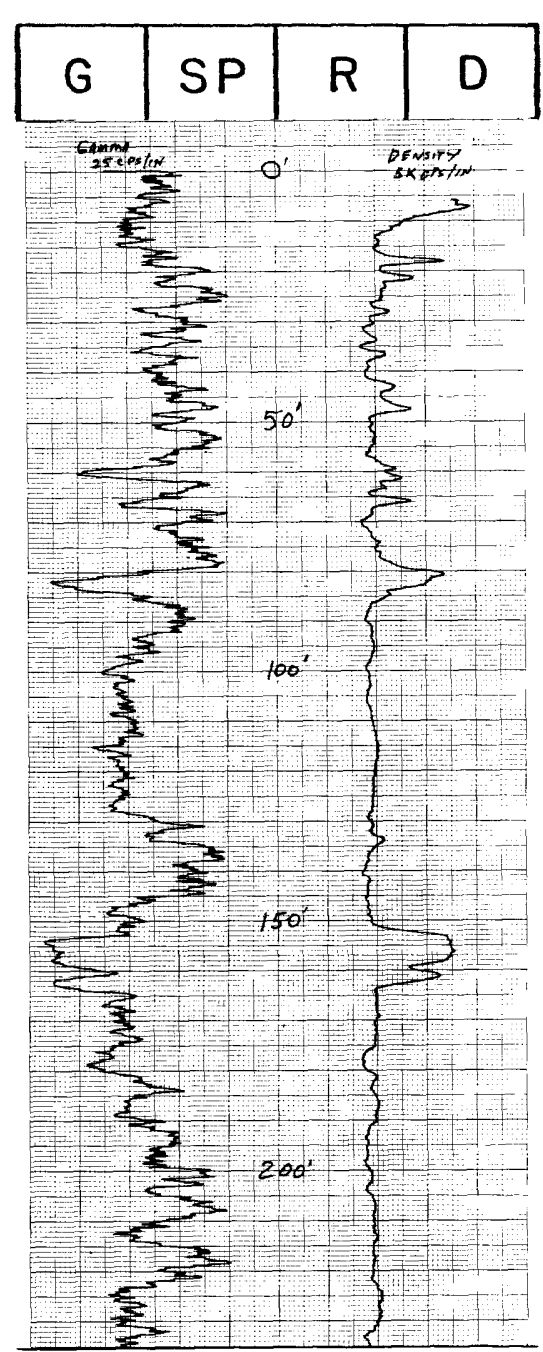

$10^{\prime} T^{1 \prime}$

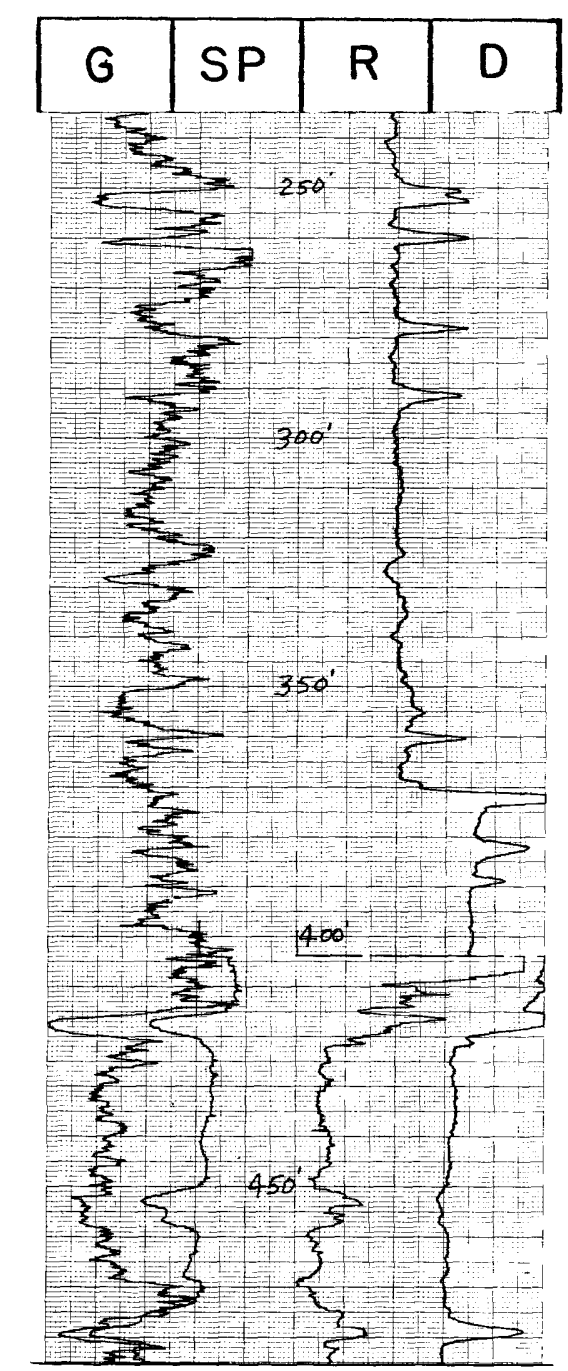


Hole no. R-14-HG

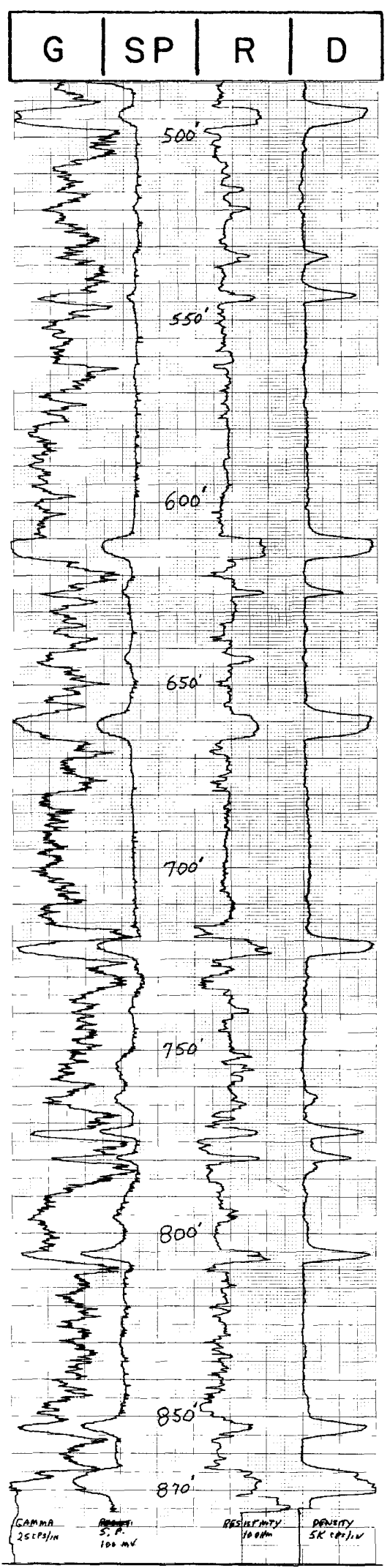

(continued)

\begin{tabular}{l|l|l|l}
$G$ & $S P$ & $R$ & $D$ \\
\hline
\end{tabular}


U.S. GEOLOGICAL SURVEY

GEOPHYSICAL LOG, MOFFAT COUNTY, COLORADO HAMILTON QUADRANGLE

Hole no. $\mathrm{H}-30-\mathrm{H}$ Date logged 8/6/77 Ground elevation 7,135'

T. 4 N., R. 90 W., Sec. $21:$ 3,450' f w $1,250^{\prime}$ f $s$

Drilling medium mud Drilled depth 1,000' Fluid level_ $1^{\prime}$

Logging company Savage_Logging speed 40'/min. Logged depth 1,000'

Natural gamma (G)

Scale $4 \mathrm{cps} / \mathrm{in} ; 40 \mathrm{cps} / \mathrm{in}$ T.C. 3

Density (gamma-gamma) (D)

Scale $1 \mathrm{~K} \mathrm{cps/in}$

T.C. 3

Spontaneous potential (SP) Scale none

Single point resistance (R) Scale $40 \mathrm{ohms} / \mathrm{in}$; $80 \mathrm{ohms} / \mathrm{in}$

Remarks: Resistance scale rerun from $180^{\prime}$ to the surface at 80 ohms/in.

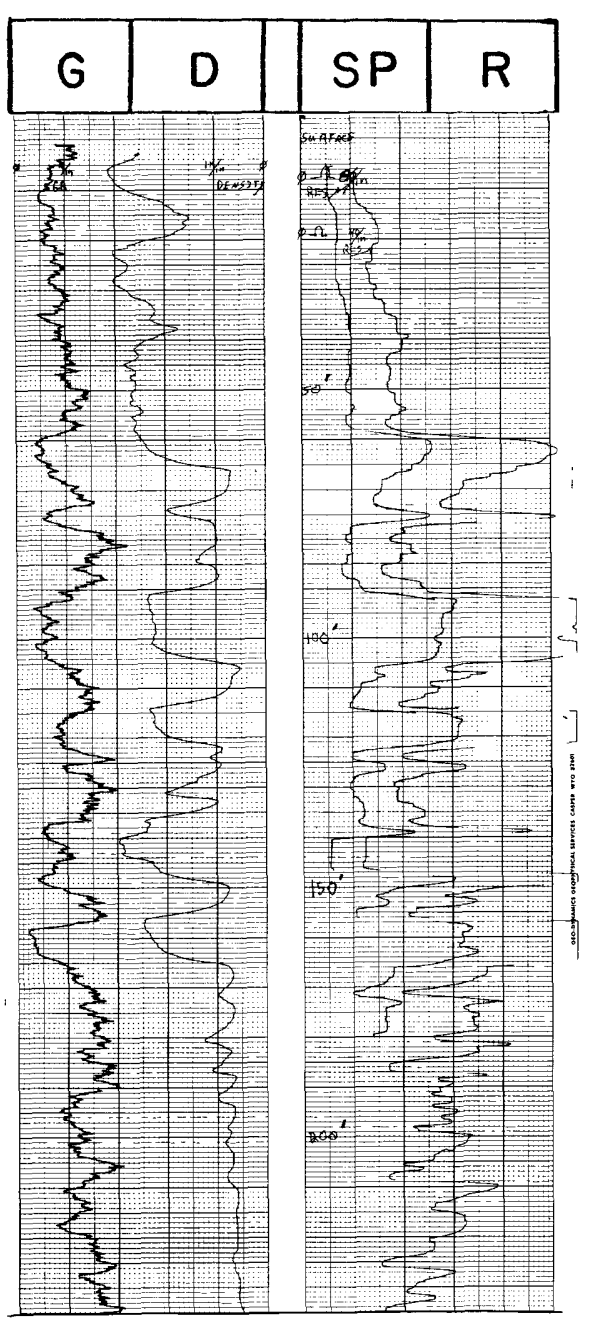

$10^{\prime} \Gamma^{\prime \prime}$

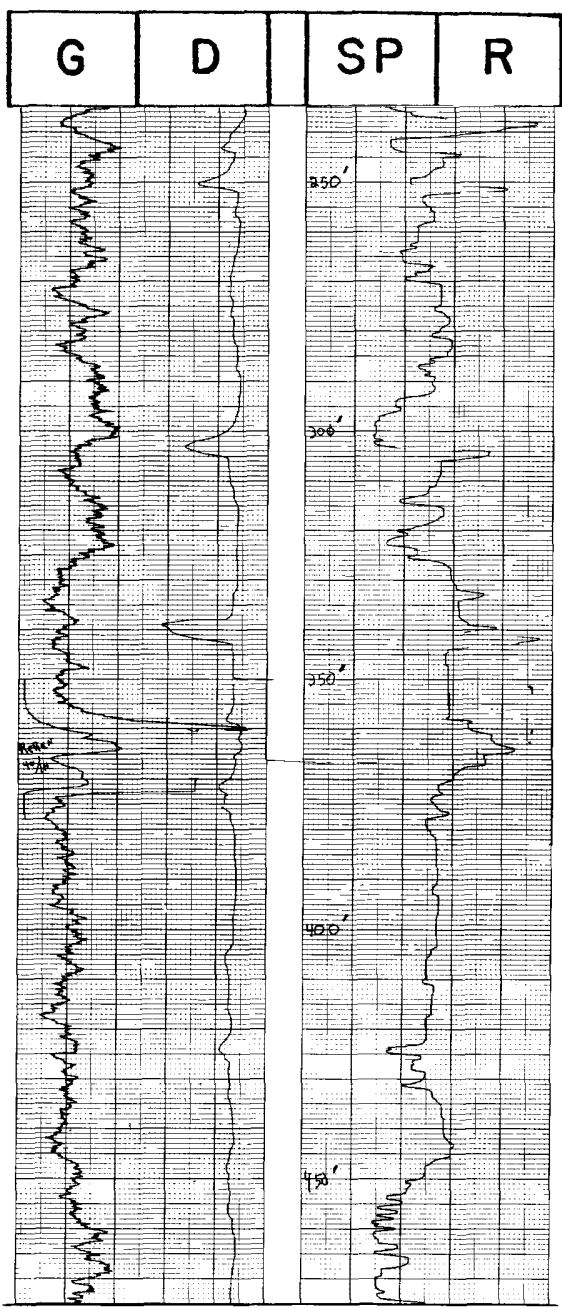


Hole no. $\mathrm{H}-30-\mathrm{H}$

(continued)
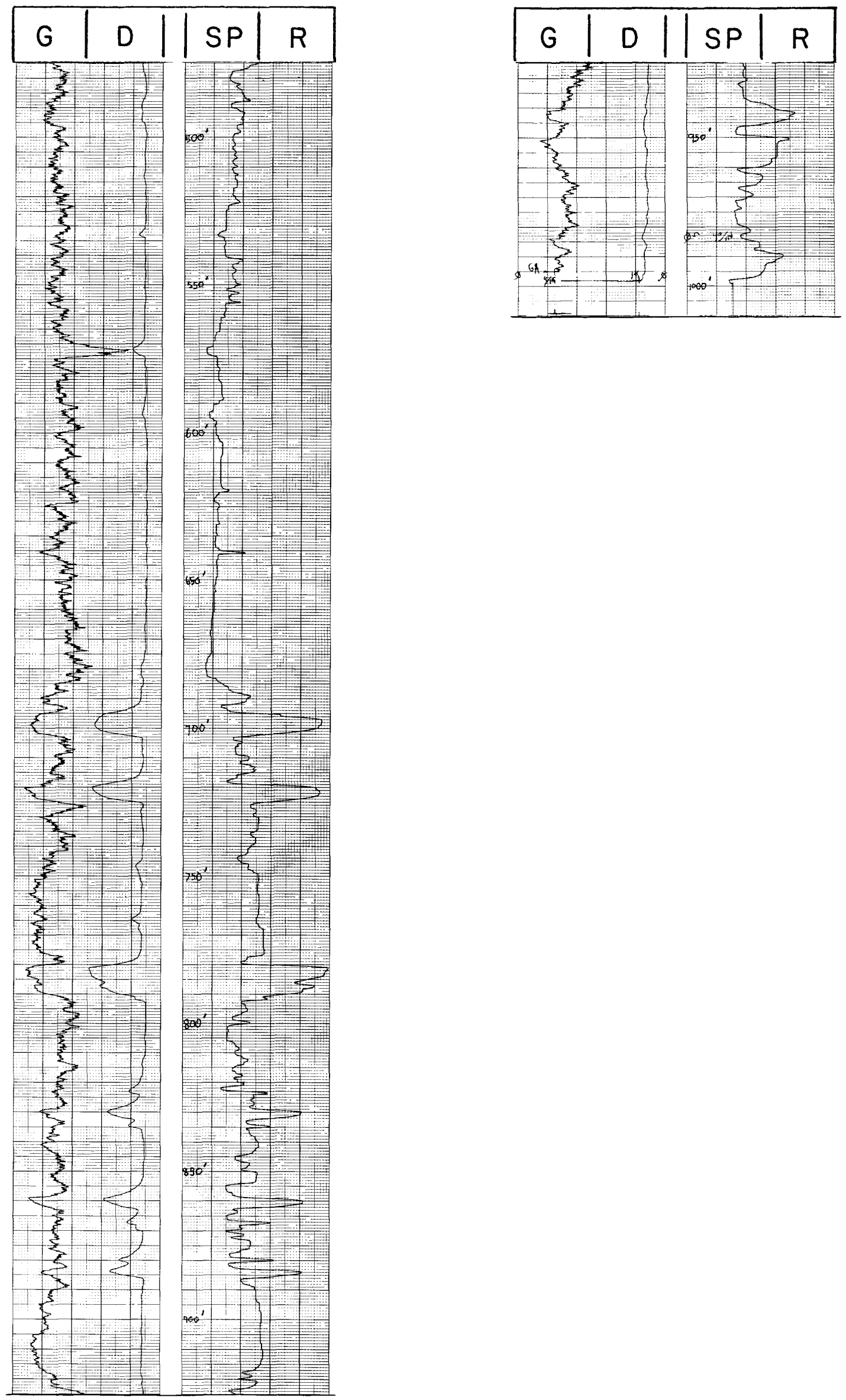
U. S. GEOLOGICAL SURVEY

GEOPHYSICAL LOG, MOFFAT COUNTY, COLORADO PAGODA QUADRANGLE

Hole no. H-31-P Date logged 8/5/77_Ground elevation 8,442'

T. 3 N., R. 90 W., Sec. 3 : 4,060 f w 1, 1,425'f s 1

Drilling medium foam Drilled depth 985' Fluid level 402'

Logging company_Rocky Mtn. Logging speed_20'/min. Logged depth 946'

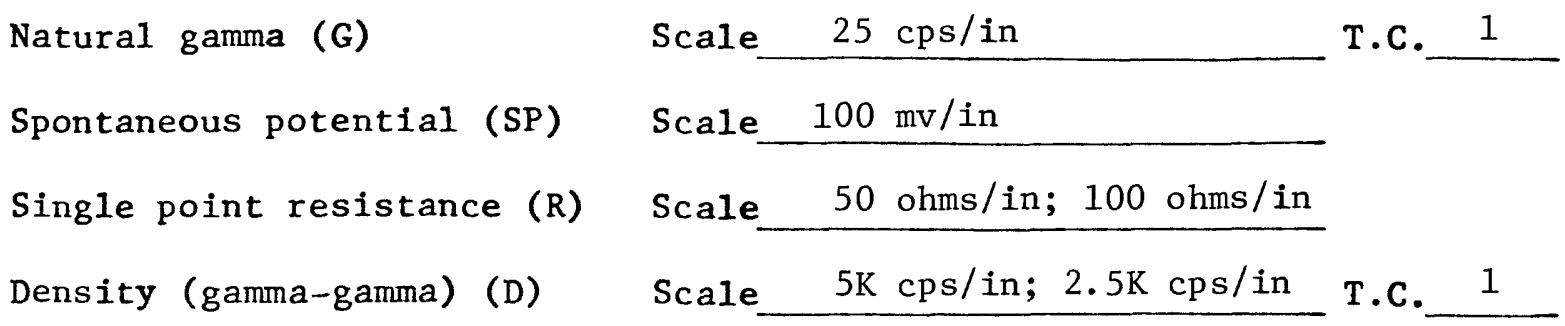

Remarks: Actual logged depth is 946'. The straight line responses of the logs between $950^{\prime}$ and 946', on the chart paper, clearly indicate that too much cable had been let out, and that the probe was not moving during that interval.
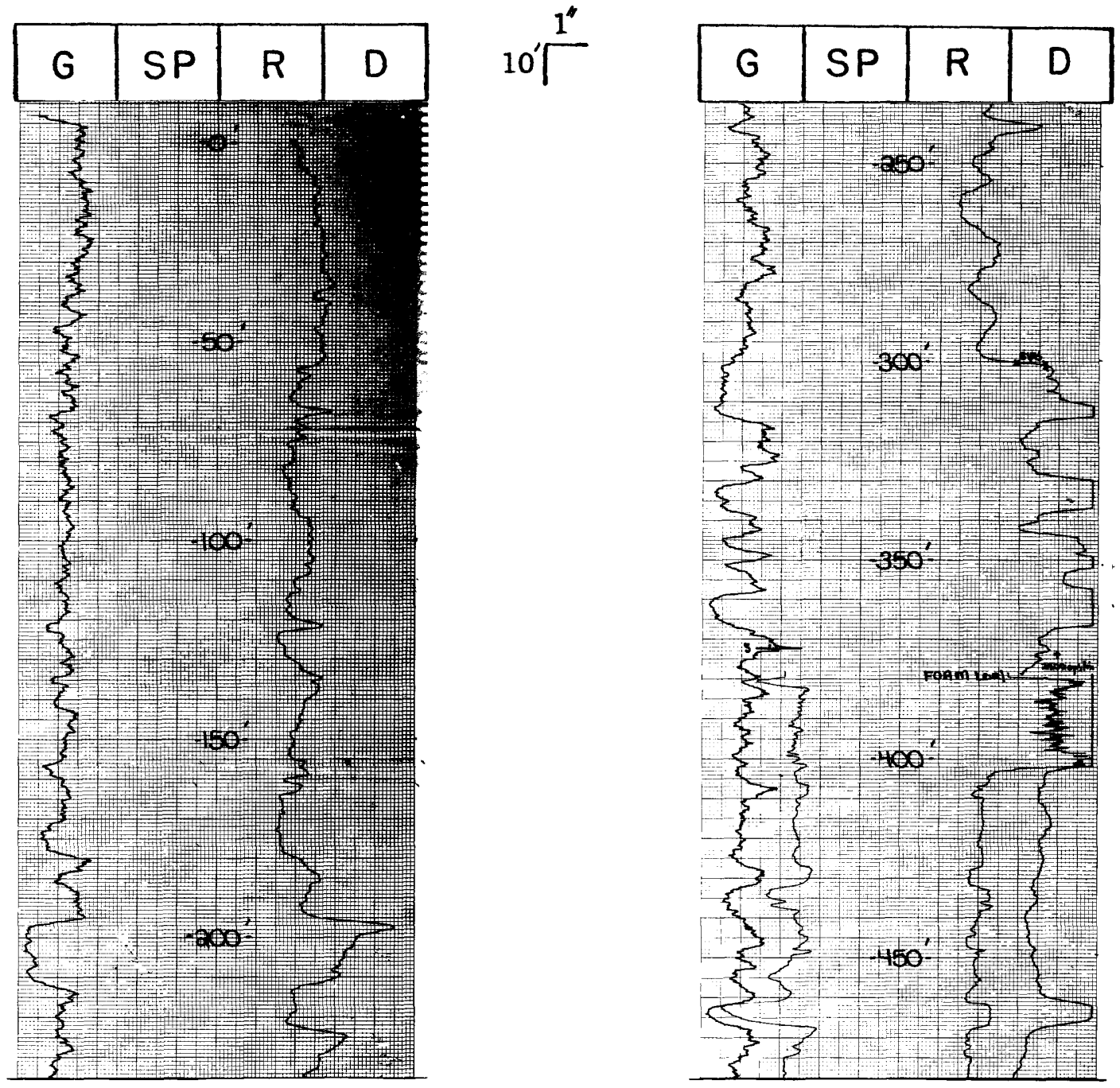
U. S. GEOLOGICAL SURVEY

GEOPHYSICAL LOG, MOFFAT COUNTY, COLORADO HAMILTON QUADRANGLE

Hole no. $\mathrm{H}-32-\mathrm{H}$ Date logged 8/8/77_ Ground elevation 8,135'

T. 4 N., R. 90 W., Sec. 32: 1,775' f v $1,3,390^{\prime}$ f s 1

Drilling medium foam Drilled depth 631'_ Fluid level_ 217'

Logging company Rocky Mtn. Logging speed 20'/min. Logged depth $627^{\prime}$

Natural gamma (G) Scale $25 \mathrm{cps} / \mathrm{in} \quad$ T.C. 1

Spontaneous potential (SP) Scale $100 \mathrm{mv} / \mathrm{in}$

Single point resistance (R) Scale $100 \mathrm{ohms} / \mathrm{in}$

Density (gamma-gamma) (D) Scale $5 \mathrm{~K} \mathrm{cps/in;} 2.5 \mathrm{~K} \mathrm{cps} / \mathrm{in}$ T.C. 1

Remarks: Density scale changed at $197^{\prime}$ to $2.5 \mathrm{~K} \mathrm{cps} / \mathrm{in}$.

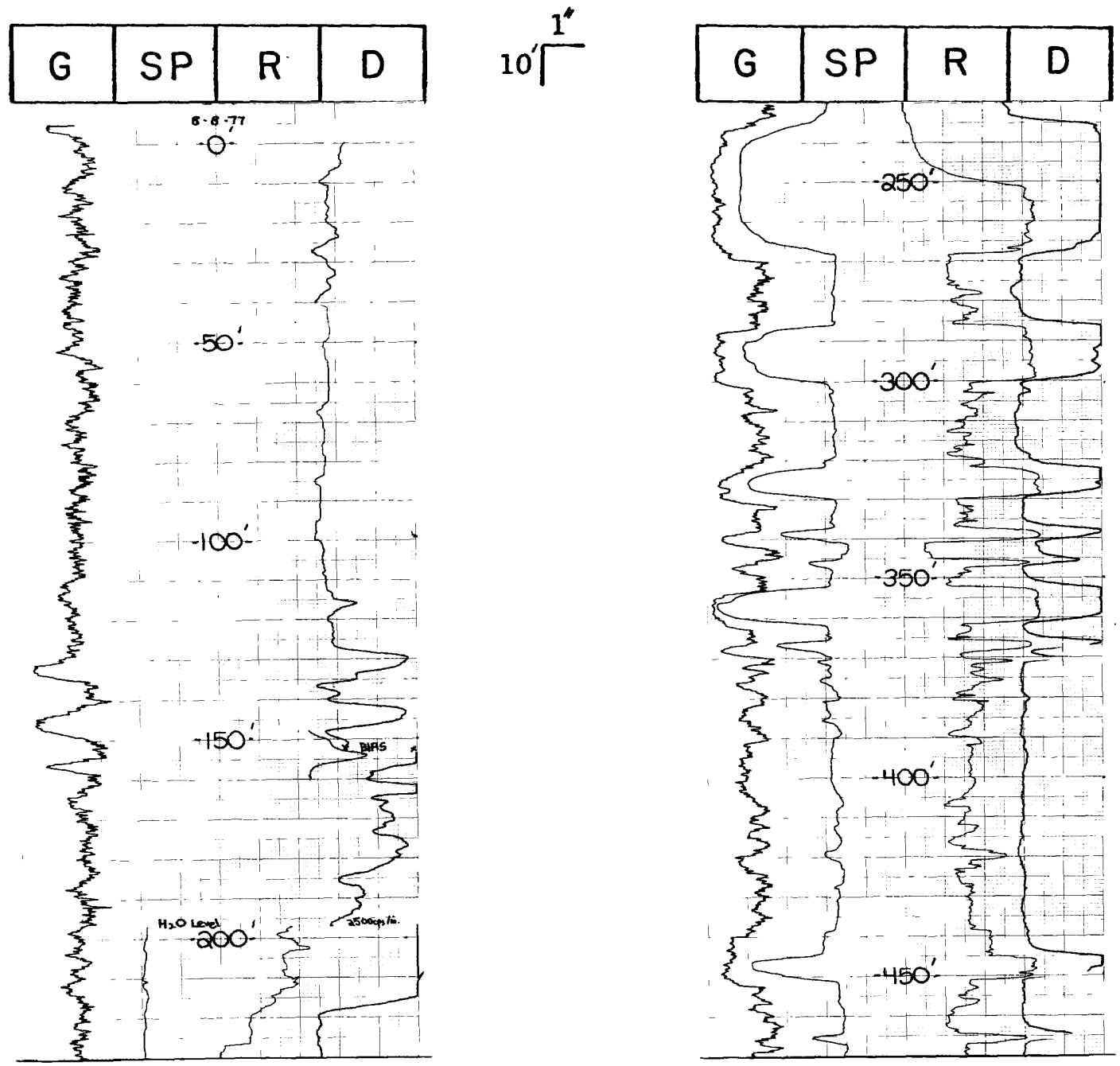


Hole no. H-31-P (continued)
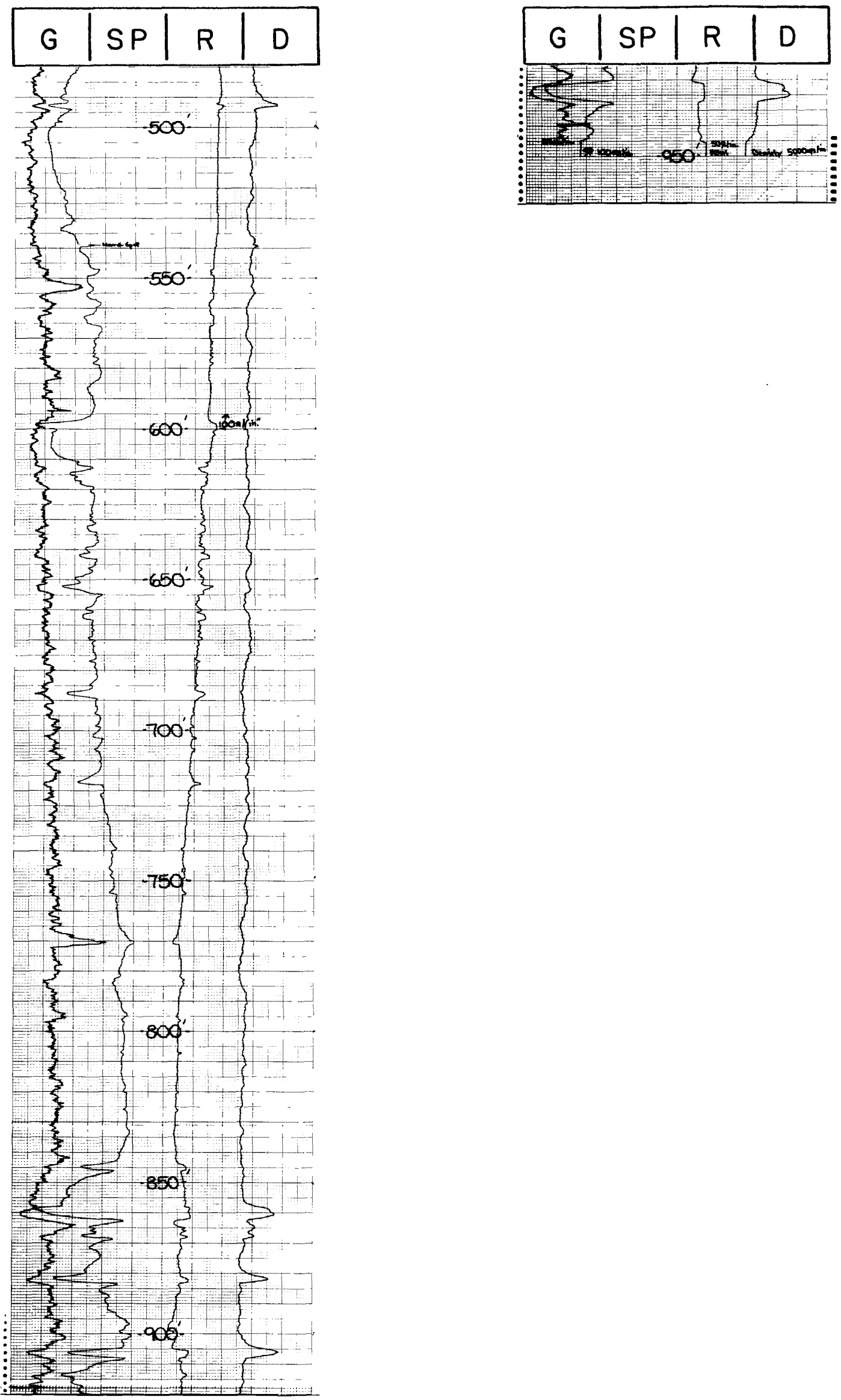
Hole no. $\mathrm{H}-32-\mathrm{H}$

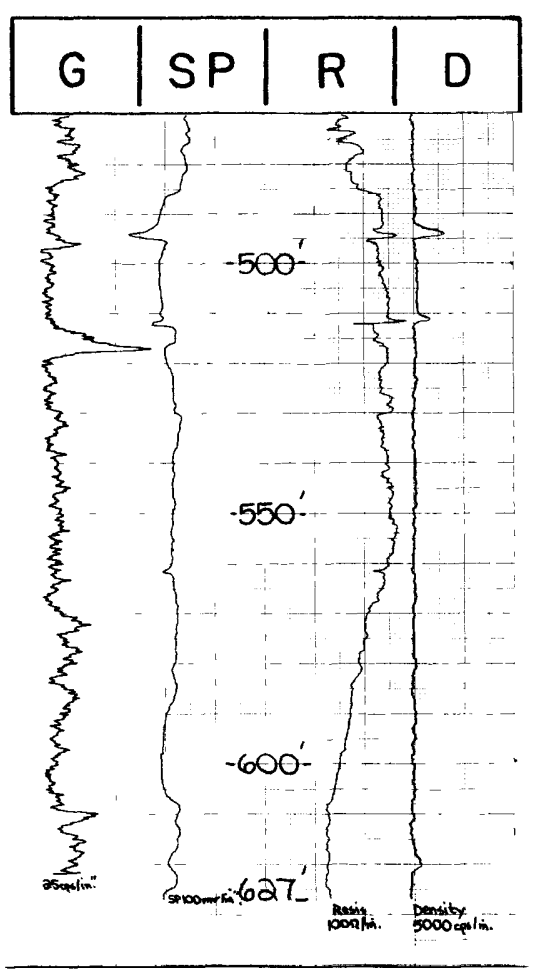

(continued)

\begin{tabular}{|l|l|l|l|}
\hline$G$ & $S P$ & $R$ & $D$ \\
\hline
\end{tabular}


U. S. GEOLOGICAL SURVEY

GEOPHYSICAL LOG, MOFFAT COUNTY, COLORADO

HAMILTON QUADRANGLE

Hole no. $\mathrm{H}-33-\mathrm{H}$ Date logged $8 / 12 / 77$ Ground elevation $8,060^{\prime}$

T. 4 N., R. 91 W., Sec. $25:$ 2,720' f w. 1, 2,950'f s 1

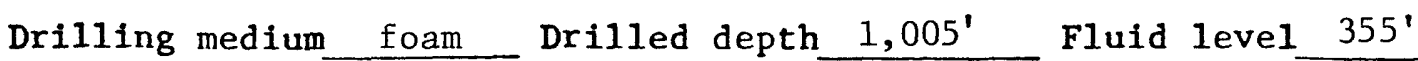

Logging company Rocky Mtn. Logging speed 20'/min. Logged depth $997^{\prime}$

$\begin{array}{lll}\text { Natural gamma (G) } & \text { Scale } 25 \mathrm{cps} / \mathrm{in} & \text { T.C. } 1 \\ \text { Spontaneous potential (SP) } & \text { Scale } 100 \mathrm{mv} / \mathrm{in} \\ \text { Single point resistance (R) } & \text { Scale } 25 \mathrm{ohms} / \mathrm{in} \\ \text { Density (gamma-gamma) } & \text { (D) } & \text { Scale } 5 \mathrm{~K} \mathrm{cps} / \mathrm{in} ; 2.5 \mathrm{~K} \mathrm{cps} / \mathrm{in} \text { T.C. } 1\end{array}$

Remarks: Actual logged depth is 997'. The straight line responses of the logs

between $1,003^{\prime}$ and $997^{\prime}$, on the chart paper, clearly indicate that too much

cable had been let out, and that the probe was not moving during that interval.

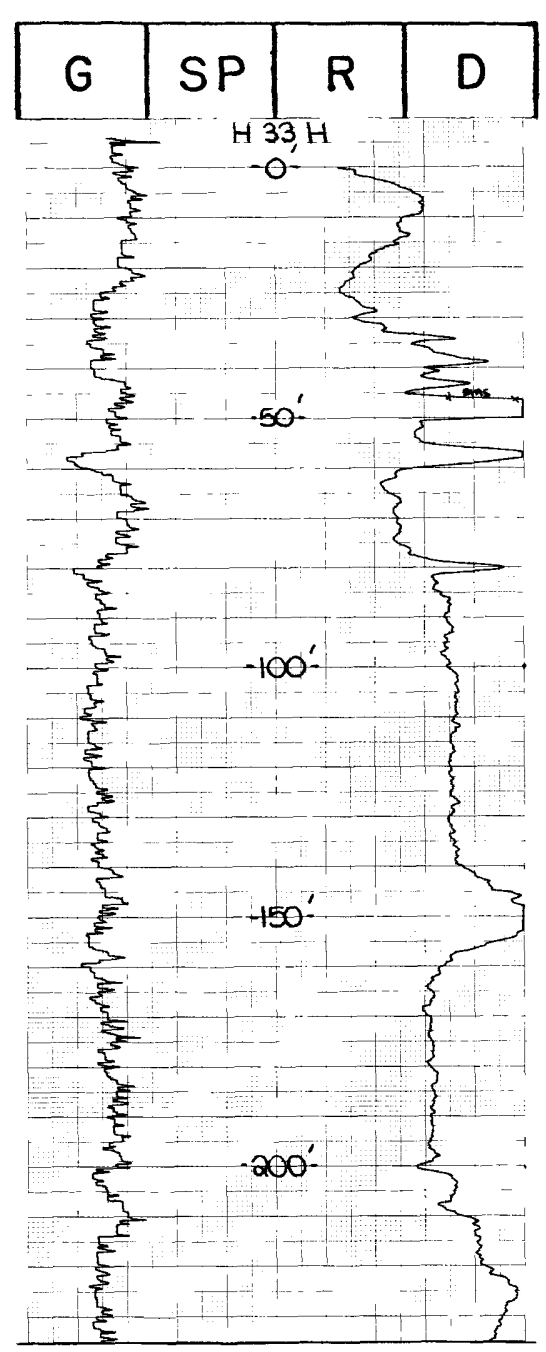

$10^{\prime} \prod^{1 \prime}$

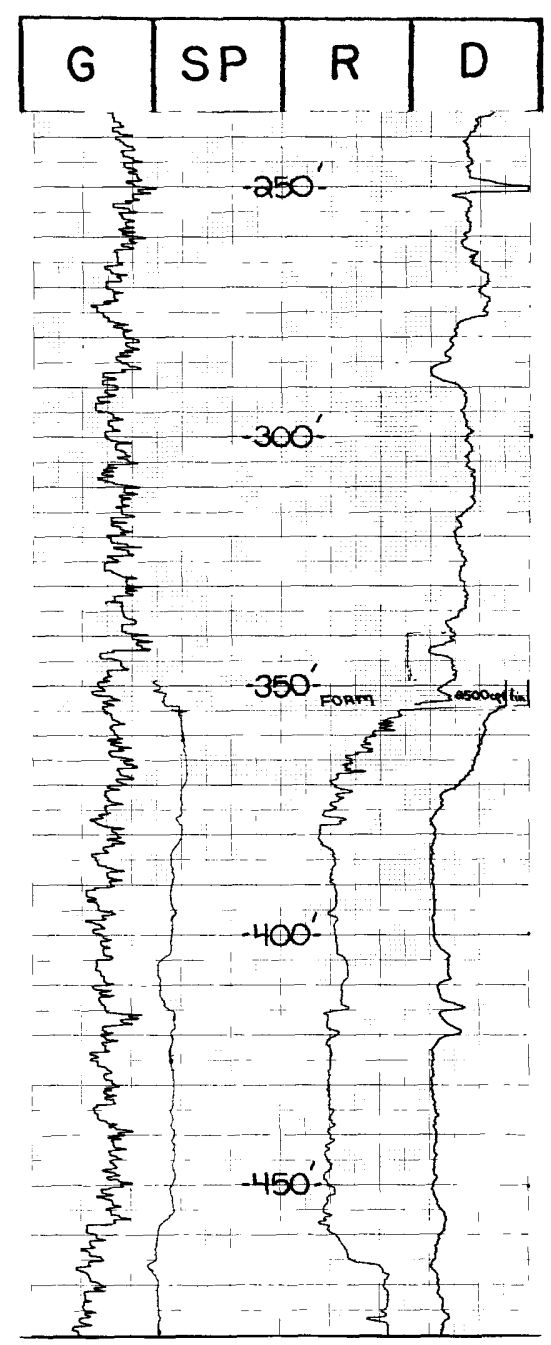


Hole no. $\mathrm{H}-33-\mathrm{H}$

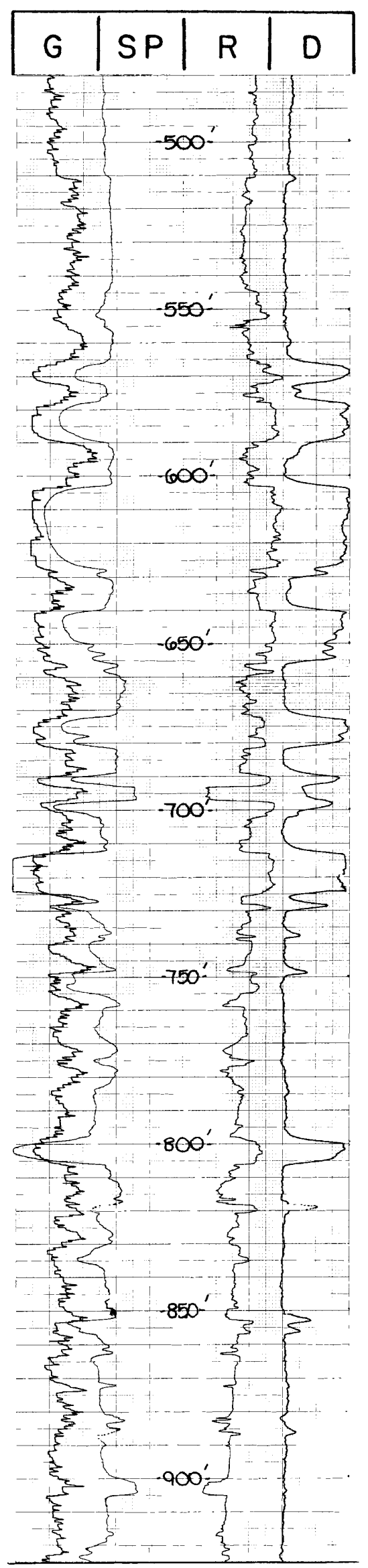

(continued)

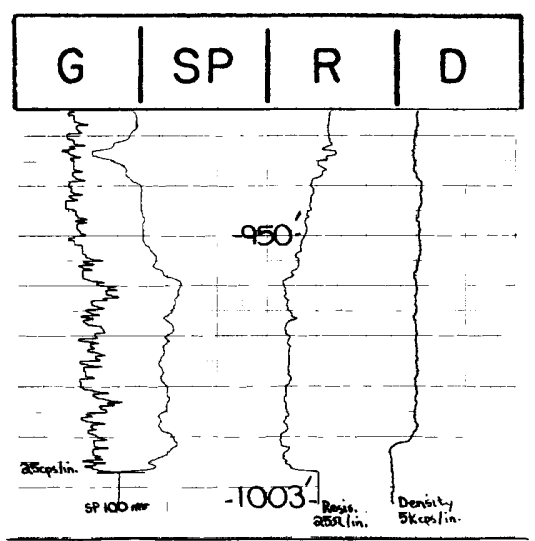


U. S. GEOLOGICAL SURVEY

GEOPHYSICAL LOG, MOFFAT COUNTY, COLORADO

HAMILTON QUADRANGLE

Hole no. $\mathrm{H}-34-\mathrm{H}$ Date logged 8/12/77_ Ground elevation 7,725'

T. 4 N., R. 91 W., Sec. $27:$ 4,350' f w 1, 5,025'f s 1

Drilling medium_foam_ Drilled depth_520'_ Fluid level 100'

Logging company Rocky Mtn. Logging speed 20'/min. Lógged depth 507'

Natural gamma (G)

Spontaneous potential (SP) Scale $50 \mathrm{mv} /$ in

Single point resistance (R) Scale $10 \mathrm{ohms} / \mathrm{in} ; 25 \mathrm{ohms} / \mathrm{in}$

Density (gamma-gamma) (D) Scale $5 \mathrm{~K} \mathrm{cps/in;} 2.5 \mathrm{~K} \mathrm{cps} / \mathrm{in}$ T.C. 1

Remarks: Resistance scale changed at $210^{\prime}$ to $25 \mathrm{ohms} / \mathrm{in}$. Density scale changed at $100^{\prime}$ to $2.5 \mathrm{~K} \mathrm{cps} / \mathrm{in}$.

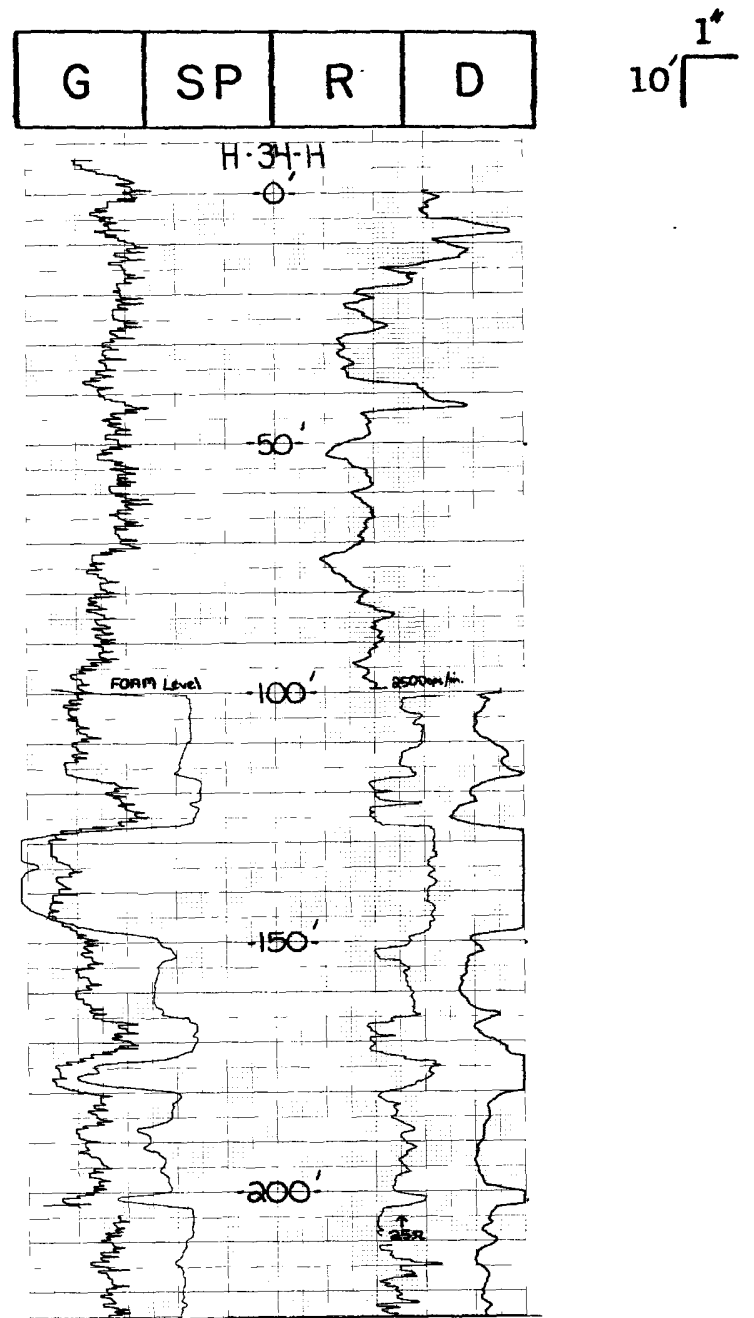

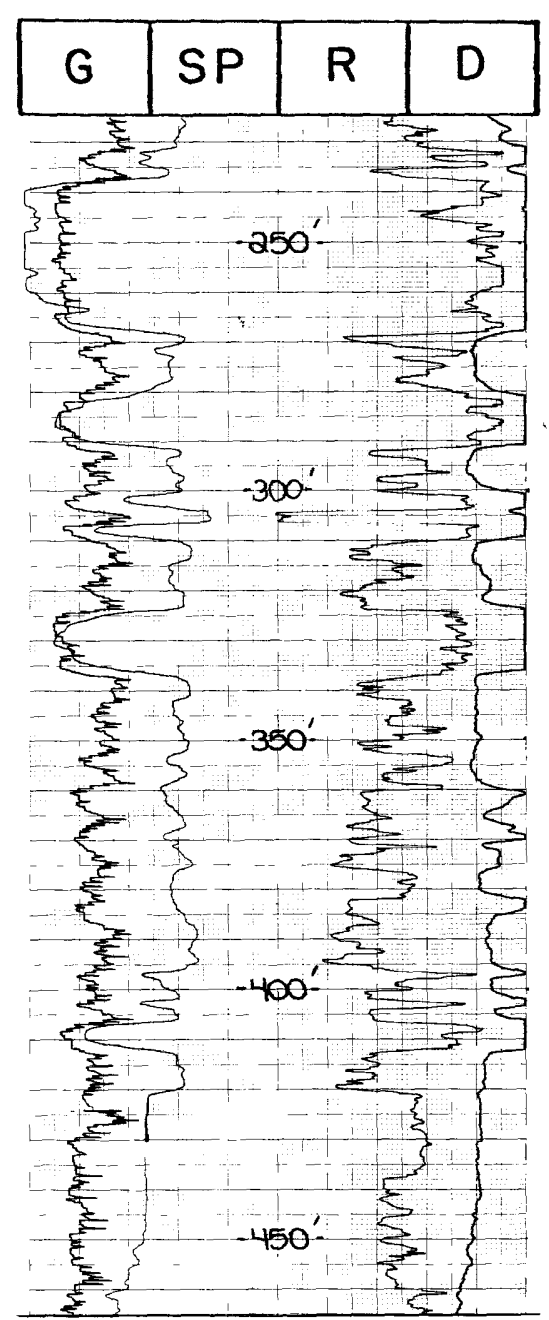


Hole no. $\mathrm{H}-34-\mathrm{H}$

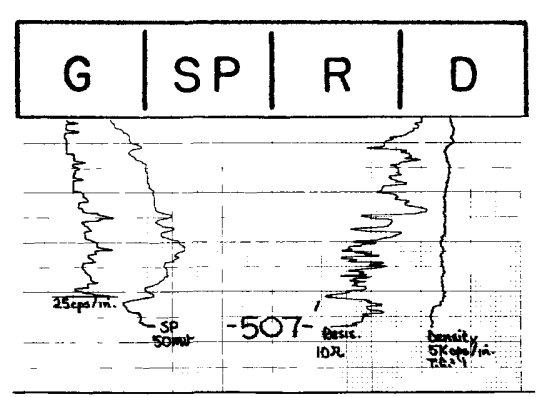

(continued)

\begin{tabular}{|l|l|l|l|}
\hline$G$ & $S P$ & $R$ & $D$ \\
\hline
\end{tabular}




\section{U. S. GEOLOGICAL SURVEY}

GEOPHYSICAL LOG, MOFFAT COUNTY, COLORADO HAMILTON QUADRANGLE

Hole no. $\mathrm{H}-35-\mathrm{H}$ Date logged $8 / 10 / 77$ Ground elevation 7,262'

T. 4 N., R. 91 W., Sec. 13: 2,775' f w $1,930^{\prime}$ f s 1

Drilling medium mud Drilled depth 1,300'_Fluid level $1^{\prime}$

Logging company_Rocky Mtn. Logging speed 20'/min. Logged depth.1,276'

$\begin{array}{lll}\text { Natural gamma (G) } & \text { Scale } 25 \mathrm{cps} / \mathrm{in} & \text { T.C. } 1 \\ \text { Spontaneous potential (SP) } & \text { Scale } 50 \mathrm{mv} / \mathrm{in} \\ \text { Single point resistance (R) Scale } 50 \mathrm{ohms} / \mathrm{in} & \text { T.C. } 1 \\ \text { Density (gamma-gamma) (D) } & \text { Scale } 5 \mathrm{~K} \mathrm{cps/in}\end{array}$

Remarks: Actual logged depth is $1,276^{\prime}$. The straight line responses of the logs between $1,281^{\prime}$ and $1,276^{\prime}$, on the chart paper, clearly indicate that too much cable had been let out, and that the probe was not moving during that interval.
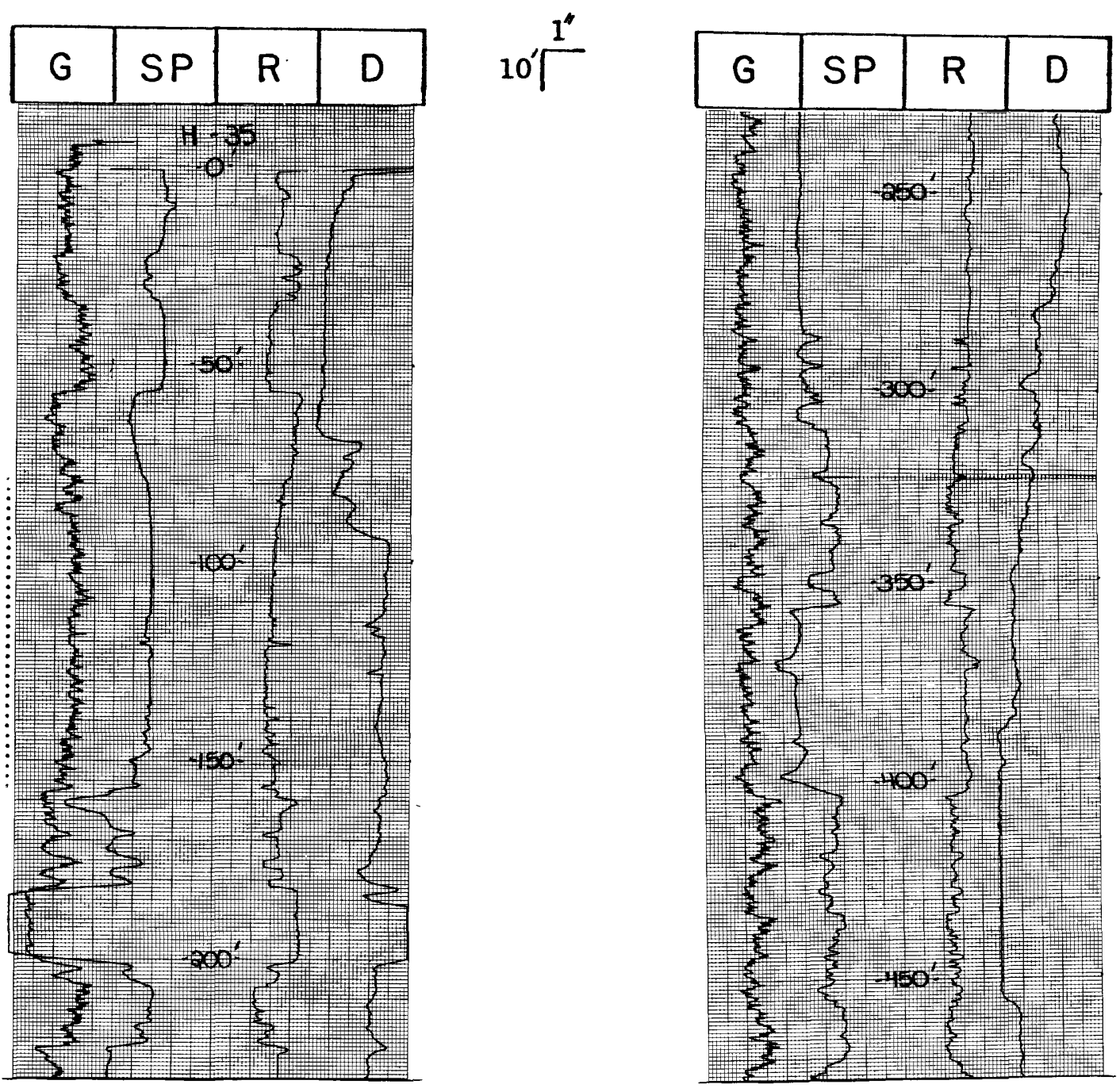
Hole no. $\mathrm{H}-35-\mathrm{H}$

(continued)
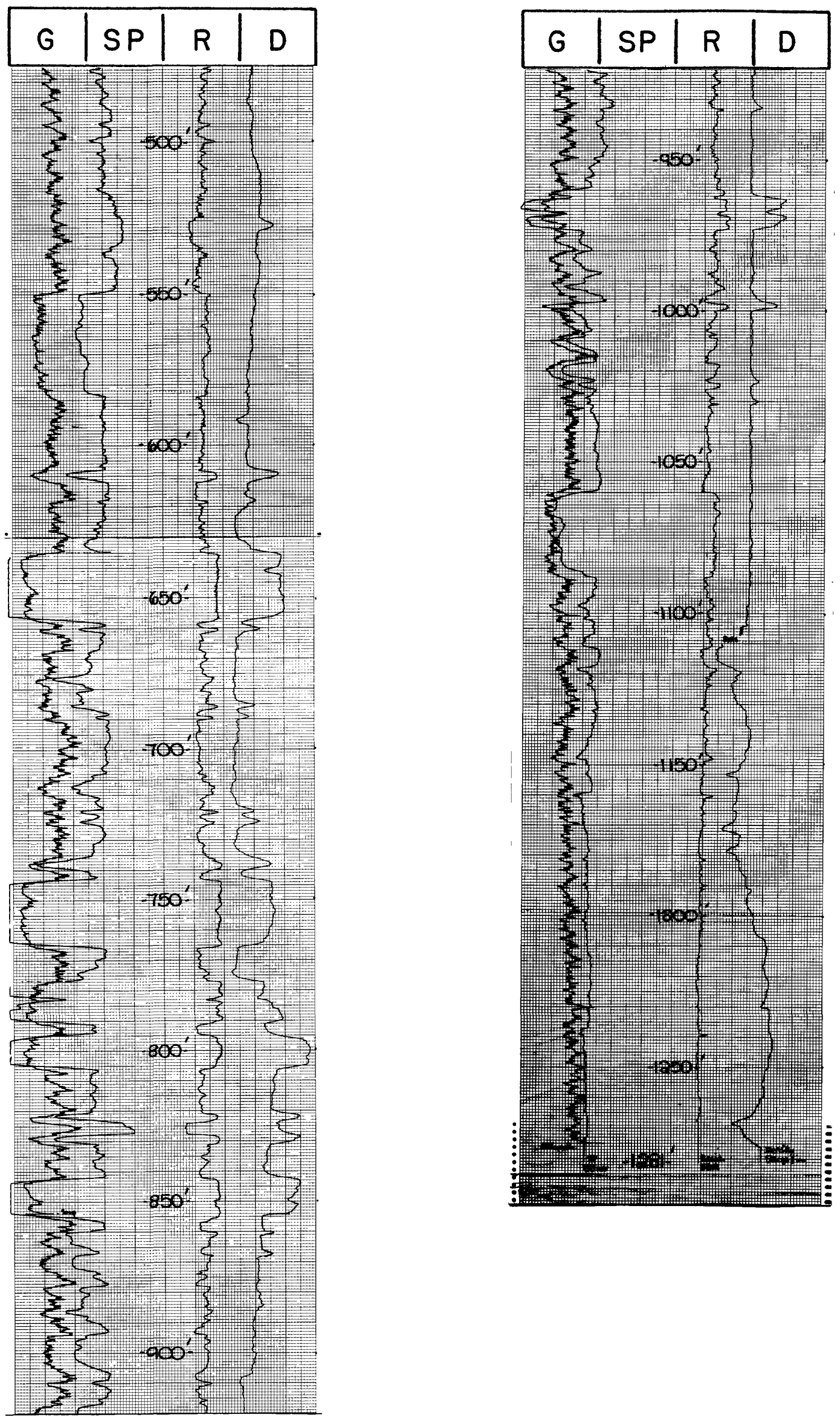